\title{
Volatile and phenolic profiles of traditional Romanian apple brandy after rapid ageing with different wood chips
}

by Coldea, T.E., Socaciu, C., Mudura, E., Socaci, S.A., Ranga, F., Pop, C.R., Vriesekoop, F. and Pasqualone, A.

Copyright, publisher and additional Information: This is the author accepted manuscript. The final published version (version of record) is available online via Elsevier.

This version is made available under the CC-BY-ND-NC licence:

https://creativecommons.org/licenses/by-nc-nd/4.0/legalcode

Please refer to any applicable terms of use of the publisher

DOI: https://doi.org/10.1016/j.apsoil.2019.103433

Coldea, T.E., Socaciu, C., Mudura, E., Socaci, S.A., Ranga, F., Pop, C.R., Vriesekoop, F. and Pasqualone, A. 2020. Volatile and phenolic profiles of traditional Romanian apple brandy after rapid ageing with different wood chips. Food Chemistry, 320, 126643. 
1 Volatile and Phenolic Profiles of Traditional Romanian Apple Brandy after Rapid

2 Ageing with Different Wood Chips

3

4 Teodora Emilia Coldea ${ }^{*}$, Carmen Socaciu ${ }^{2}$, Elena Mudura ${ }^{1}$, Sonia Ancuța Socaci ${ }^{3}$,

5 Floricuța Ranga ${ }^{2}$, Carmen Rodica Pop ${ }^{3}$, Frank Vriesekoop ${ }^{4}$, Antonella Pasqualone ${ }^{5}$

6

7 1. Department of Food Engineering, University of Agricultural Sciences and Veterinary

8 Medicine Cluj-Napoca, 3-5, Manastur Street, 400372 Cluj-Napoca, Romania

9 2. Department of Food Chemistry and Biochemistry, University of Agricultural Sciences

10 and Veterinary Medicine Cluj-Napoca, 3-5, Manastur Street, 400372 Cluj-Napoca,

11 Romania

12 3. Department of Food Science, University of Agricultural Sciences and Veterinary

13 Medicine Cluj-Napoca, 3-5, Manastur Street, 400372 Cluj-Napoca, Romania

14 4. Department of Food Technology and Innovation, Harper Adams University, Newport, $15 \quad$ TF10 8NB, United Kingdom

16 5. Department of Soil, Plant and Food Sciences, University of Bari 'Aldo Moro', Via

17 Amendola, 165/A, 70126 Bari, Italy

18 * Corresponding author: teodora.coldea@usamvcluj.ro (T. Coldea); Department of Food

19 Engineering, University of Agricultural Sciences and Veterinary Medicine Cluj-

20 Napoca, 3-5, Manastur Street, 400372 Cluj-Napoca, Romania 
23 Abstract: The aim of this work was to find differences in the volatile and phenolic profiles

24 of the traditional Romanian apple brandy pălinca aged with various species of wood chips.

25 Seven types of wood species, two types of oak (Quercus petraea and Quercus robur), plus

26 sweet chestnut, mulberry, walnut, fir and cherry, were considered. The majority of volatile

27 compounds characterizing the aroma profile of pălinca were esters, particularly ethyl esters,

28 with ethyl isobutyrate, ethyl isovalerate, ethyl caproate, ethyl octanoate and ethyl decanoate

29 as the most abundant. The most important source of catechin was cherry wood. Rutin and

30 juglone were solubilised only in walnut wood aged brandy. Vanillin, increased significantly

31 in chestnut aged apple brandy. Given the cost and difficulty in handling wooden barrels, and

32 as an alternative being able to select from a range of specific wooden chips, this work could

33 potentially guide actors in beverage industry to less expensive alternatives.

35 Keywords: apple brandy; pălinca; seasoned wood; polyphenols; volatile compounds.

36 Highlights:

37 - Pălinca is a traditional double batch-distilled Romanian fruit brandy.

38 - Rapid ageing of pălinca impacts both the volatile and phenolic profiles regardless of 39 the wood types employed.

- Fir and cherry wood contributed the largest quantity of phenolic compounds to pălinca.

- The lowest contribution to volatile profile of pălinca was given by the mulberry wood.

- The esters of fatty acids contributed the most to the volatile profile of pălinca. 


\section{Introduction}

Since ancient times, Romania has a strong tradition of producing fruit brandies, with resurgence in both producing and consumption, especially in areas where fruits are grown and harvested (Salanţă, Tofană, Pop, Pop, Coldea \& Mudura, 2017). The use of wood in the ageing of spirits, including fruit brandies, has a great influence on their final taste and aroma (Canas, Caldeira, Anjos, Lino, Soares \& Belchior, 2016).

Wood-ageing is one of the costliest factors influencing the quality of distilled beverages.

Traditional wood-ageing involves the use of wooden barrels, typically constructed from appropriate oak species, of varying volumes, at lengthy periods of time. Despite the classical method of wood-ageing, several alternative techniques have been tested in order to reduce the ageing period, considering both the economical point of view and the notion of environmental sustainability (Cîrstea, Moldovan-Teselios, Cîrstea, Turcu \& Darab, 2018).

These alternative techniques include the use of ultrasound to enhance the extraction of wood compounds in wine production (Tao, Zhang \& Sun, 2014) and spirit production (Caldeira, Pereira, Clímaco, Belchior \& De Sousa, 2004; Delgado-González, Sánchez-Guillén, GarcíaMoreno, Rodríguez-Dodero, García-Barroso \& Guillén-Sánchez, 2017), the application of electric fields (Zhang, Zeng, Sun, Yu, Yang \& Ma, 2013) and high pressure (Tchabo, Ma, Kwaw, Zhang, Xiao \& Tahir, 2017) as efficient, non-thermal and cost-effective alternatives. Since the International Organisation of Vine and Wine (OIV) approved the use of wood staves or sticks (as alternatives to barrels) to hasten the ageing period, different methods have been applied on alcoholic beverages to enhance their sensorial properties, the flavour and phenolic profiles. Recently, greater attention has been given to the use of wooden fragments 
and even powders to facilitate a rapid ageing of wines (Cabrita, Barrocas Dias \& Costa Freitas, 2011), brandies (Canas, et al., 2016; Rodríguez-Solana, Rodríguez-Freigedo, Salgado, Domínguez \& Cortés-Diéguez, 2017), and apple ciders (Fan, Xu \& Yu, 2006) in order to achieve a significant reduction in the overall maturation period. The cost and complexities of barrel stock management, together with the reduction in maturation time, has guided the industry to engage with these cost-effective alternatives. While these wood products typically undergo some sort of heat treatment (toasting or charring); the use of untoasted wood is not unprecedented (Sanz et al., 2010a). Traditional handicrafts of wooden fragments represent important components with notable cultural or religious significance in East European countries, dating back many centuries. During the ageing process of some local fruit brandies (called horinca or pălinca) originated from the Maramureș County in Northern Romania, dried, unheated, wooden handicraft objects, typically made from polar or mulberry, are added as miniatures into the bottles (Dippong, Avram \& Mihali, 2019). The ageing period for this wood embedding technique lasts between some days to few months, depending on each product.

The abundant and diverse forests in Eastern Europe facilitate a diverse choice of readily available wood species, makes for easy access to both oak and alternative wood species for the ageing process of alcoholic beverages. Oak (Quercus spp.) is the most commonly used wood in tight cooperage with a great beneficial influence on the volatile and phenolic composition (Alañón, Castro-Vázquez, Díaz-Maroto, Hermosín-Gutiérrez, Gordon \& PérezCoello, 2011). Quercus robur (aka pedunculate oak) and Quercus petraea (aka sessile oak) are the most commonly used European oak species in tight cooperage (Alañón et al., 2011). 
The availability and extractability of ellagitanins, phenolic- and volatile compounds, together with the water tightness of the oak tyloses, make some oak species the preferred wood for cooperage for the wine and distilled industry. However, producers will also consider wood alternatives such as chestnut (Castanea sativa), cherry (Prunus avium), walnut (Juglans regia), acacia (Robinia pseudacacia), mulberry (Morus alba and Morus nigra), ash (Fraxinus excelsior and Fraxinus Americana), beech (Fagus sylvatica), alder (Alnus glutinosa), lime (Tilia cordata) and fir (Abies alba) for beverage cooperage (Alañón et al., 2011; De Rosso, Cancian, Panighel, Vedova, \& Flamini, 2009; Martínez-Gil, del AlamoSanza, Sánchez-Gómez \& Nevares, 2018). While oak is used in the vast majority of wooden barrels for alcohol maturation; chestnut is a very distant second commonly used wood. It has a suitable porosity, which facilitates the micro oxygenation of the spirit and the abundant release of polyphenols into the distillate (Canas et al., 2016). Cherry wood has a high porosity and is highly oxidative, which has been successfully utilised for short ageing periods (Chinnici, Natali, Bellachioma, Versari \& Riponi, 2015; Magalhães et al., 2011). Mulberry wood is tender and elastic, having medium porosity and a low release of compounds during ageing (De Rosso et al., 2009). European walnut tree is one of the darkest wood species (Liu, Timar, Varodi \& Sawyer, 2017) and is recognized for its high and distinct antioxidant activity (Diouf, Merlin, \& Perrin, 2006).

Wood for the maturation of spirits is exposed to a heat treatment associated with the typical manufacture of wooden barrels when the staves are being bent into the quintessential convex and bulging shape of a barrel, which represents the firing process (Schahinger \& Rankine, 2005). A simple extension of the firing process converts into the toasting process 
111 or the heat treatment can be further extended into a charring process (Singleton, 1995). As a

112 result of the heat treatment, the toasted wood might release a greater amount of polyphenols

113 which maybe due to the protective role of Maillard reaction compounds, such as melanoidins,

114 formed during toasting process (Magalhães et al., 2011; Zhang, Cai, Duan, Reeves \& He,

115 2015). Polyphenols have antioxidant activity (Alañón et al., 2011). Furthermore, Maillard

116 reaction compounds (such as pyrazines and other furanic compounds) are partially

117 responsible for the brandy colour, as well as cacao and caramel aromas (Canas et al., 2016;

118 Rodríguez Madrera, Gomis \& Mangas Alonso, 2003). However, some Maillard reaction

119 compounds, including furfural, present a carcinogenic risk (Parisi \& Luo, 2018). Some of

120 these products are also formed during the distillation process especially when classical

121 method by direct heating of the mash is applied (Coldea, Socaciu, Pârv \& Vodnar, 2011) and

122 during the toasting process of cooperage (Marques Bortoletto, Casagrande Silvello

$123 \&$ Alcarde, 2018). The more intensive the toasting process, the greater the amount of these

124 compounds are formed, potentially affecting the safety of the spirit. However, no risks

125 associated with the consumption of spirits has been reported for average drinkers

126 (Monakhova \& Lachenmeier, 2012).

127 The ageing process is an important step not only for improving the sensory profile of

128 alcoholic beverages but also for gaining other characteristics of interest such as the increase

129 of antioxidant activity and the content in phenolic compounds (Alañón et al., 2011;

130 Rodríguez Madrera, Suárez Valles, Diñeiro García, Del Valle Argüelles \& Picinelli Lobo,

1312010 ) and, as a consequence, become of interest also from the technological point of view 
132 because improves the beverage complexity, limpidity, colour stability and the intensity of

133 flavour and aroma (Chinnici et al., 2015; De Rosso et al., 2009; Tao et al., 2014).

134 The main contributors to brandies' sensorial characteristics derived from wood have

135 been found to include volatile terpenoids, phenols, benzoic and cinnamic aldehydes (Canas

136 et al., 2016; De Rosso et al., 2009). Many compounds extracted from the wood originate from

137 the degradation of macromolecules by heating during cask fabrication. Phenolic compounds

138 such as vanillin and other aromatic aldehydes, influence the sensorial properties of beverages,

139 such as aroma; while furan compounds influence colour, astringency and bitterness. The

140 quality of distilled beverages is often influenced by the level of wood exposure during the

141 maturation process, which is strongly related to beverage matrix, origin and species of wood

142 used in cooperage, length of the maturation period, the wood surface area to beverage-volume

143 ratio and in the case of toasted wood, the degree of toasting (Canas et al., 2016; De Rosso et

144 al., 2009). Over time, during maturation, a physical alignment of the ethanol and water

145 molecules occurs and the distillate becomes smoother and less pungent (Rodríguez Madrera,

146 Suárez Valles \& Picinelli Lobo, 2011). A number of chemical modifications in the

147 composition of beverage take place during the process of wood maturation such as

148 evaporation, degradation of some compounds and/or reactions between distillate and wood

149 compounds, extraction of different wood compounds into distillate, and the absorption and

150 adsorption of other compounds from the spirit into the wood.

151 The current study presents an extensive research on the impact of seven different types

152 of wood chips, as an alternative way to shorten the ageing period of fruit brandies and to

153 produce differentiated, high quality products in a cost-efficient manner. 


\section{2. Materials and Methods}

\section{2.1. Materials}

Two apple varieties (Jonathan and Sinap Orlovsky in a 1:2 ratio, 2018 harvest) were used for the production of the brandy used in this study. The apple brandy was obtained locally from Ocolișel (Cluj County Transylvania region, Central part of Romania) as a fresh distillate resulting from the traditional, local method (double distillation in a copper alembic) as previously described (Coldea et al., 2014), with an ethanol content of $46.25 \% \mathrm{ABV}$.

(Prunus avium), all sourced locally in Romania. The wood fragments were naturally seasoned in open air, shielded from light, for three months without applying any thermal wood fragments were placed in $1 \mathrm{~L}$ of apple brandy and kept for 60 days, away from light at room temperature. The samples were shaken daily for 5 min during the ageing period. At the completion of the maturation period (60 days), all samples were filtered to remove all traces

171 of wood. A control apple brandy without any wood exposure was used as a reference for 172 comparison to the wood aged brandies. All experimental variables and control were set up in 173 triplicate. All the samples were kept at $-20^{\circ} \mathrm{C}$ until being analyzed.

174 All used chemicals (ethanol, methanol, acetaldehyde, ethyl acetate, 1-propanol, 2175 butanol, 1-propanol, 2-methyl-1-propanol, 1-butanol, 2-methyl-1-butanol, 3-methyl-1- 
176 butanol, furfural, 3-pentanol, acetonitrile) had purity over 99\% (Merck, Darmstadt,

177 Germany). Gallic acid and acetic acid ( $\geq 99 \%$ purity) were purchased from Sigma-Aldrich

178 (Steinheim, Germany).

179

180

2.2. GC-FID Analysis

181 Analysis of major volatile compounds in apple brandies was carried as previously

182 reported (Coldea et al., 2011) with some modifications. Samples were filtered through 0.45

$183 \mu \mathrm{m}$ nylon Whatman filters (Schleicher \& Schuell, England). An Agilent (Agilent

184 Technologies, CA, USA) gas chromatograph 6850A, fitted with an FID was employed. One

185 microliter from each sample was introduced on ZB-WAX plus (Zebrom $\left.{ }^{\mathrm{TM}}\right)$ capillary column

$186(60 \mathrm{~m} \times 0.25 \mathrm{~mm} \times 0.25 \mu \mathrm{m})$. The injector temperature was $240^{\circ} \mathrm{C}$ the carrier gas was helium

187 (flow rate $1 \mathrm{ml} / \mathrm{min}$ ) and the detector (FID) temperature was $250^{\circ} \mathrm{C}$. The initial oven

188 temperature was set at $35^{\circ} \mathrm{C}$ and then programmed as follows: $35-58^{\circ} \mathrm{C}$ (at the rate of

$18912^{\circ} \mathrm{C} / \mathrm{min}$ ), $58-85^{\circ} \mathrm{C}$ (at the rate of $3^{\circ} \mathrm{C} / \mathrm{min}$ ), $85-155^{\circ} \mathrm{C}$ (at the rate of $30^{\circ} \mathrm{C} / \mathrm{min}$ ), $155-230^{\circ} \mathrm{C}$

190 (at the rate of $200^{\circ} \mathrm{C} / \mathrm{min}$ ). The main components (methanol, acetaldehyde, ethyl acetate, 1-

191 propanol, 1-butanol, 2-butanol, 2-methyl-1-propanol, 2-methyl-1-butanol, 3-methyl-1-

192 butanol, furfural), were identified by comparing their retention times to appropriate

193 standards. For the quantitative evaluation we employed 3-pentanol as an internal standard by

194 adding $0.1 \mathrm{ml} \mathrm{3-pentanol} \mathrm{to} 10 \mathrm{ml}$ of sample. Each analyse was carried out in triplicate.

195

196

2.3. Extraction of volatile compounds for $G C-M S$ analysis 

technique (ITEX). Using a CombiPAL AOC-5000 auto sampler, $1.5 \mathrm{~mL}$ sample with $6.5 \mathrm{~mL}$ distilled water were placed in a $20 \mathrm{ml}$ headspace vial, sealed and incubated for 30 minutes at $40^{\circ} \mathrm{C}$, under continuous agitation. After incubation, the volatile compounds from the gaseous

201 phase from the vial were adsorbed repeatedly (30 strokes) into a porous polymer fibre 202 microtrap (ITEX-2-Trap-TXTA, Tenax TA 80/100 mesh) and then were thermally desorbed 203 directly into the GC-MS injector as described elsewhere (Socaci et al., 2014). All samples 204 were analysed in triplicate.

\section{4. $G C-M S$ analysis}

The separation of volatile compounds was carried out on a GC-MS QP-2010 model

208 (Shimadzu Scientific Instruments, Kyoto, Japan) (Socaci et al., 2014), employing a Zebron

ZB-5 ms capillary column of $30 \mathrm{~m} \times 0.25 \mathrm{~mm}$ i.d. and $0.25 \mu \mathrm{m}$ film thickness (Phenomenex,

210 USA). The carrier gas was helium $1 \mathrm{~mL} / \mathrm{min}$ and the split ratio 1:50. The initial oven 211 temperature was set at $40^{\circ} \mathrm{C}$ (hold for $10 \mathrm{~min}$ ), then $40-120^{\circ} \mathrm{C}$ (at the rate of $12^{\circ} \mathrm{C} / \mathrm{min}$ ), 120 $212240^{\circ} \mathrm{C}$ (at the rate of $10^{\circ} \mathrm{C} / \mathrm{min}$ ), and finally held for 5 minutes at $240^{\circ} \mathrm{C}$. The injector, ion213 source and interface temperatures were set at $250^{\circ} \mathrm{C}$. The MS detection used for the 214 qualitative analysis was performed on a quadrupole mass spectrometer operating in full scan 215 electron impact (EI) at ionization energy of $70 \mathrm{eV}$. The method was optimized in respect to 216 the extraction temperature which decreased from $60^{\circ} \mathrm{C}$ to $40^{\circ} \mathrm{C}$ and the sample volume was 217 increased from $1 \mathrm{~mL}$ to $1.5 \mathrm{~mL}$ compared to Socaci et al. (2014).

218 The identification of volatile compounds was performed by comparing their mass spectra 
with those in the NIST27 and NIST147 mass spectra libraries from the US National Institute

of Technology and Standards (NIST) and by retention indices drawn from www.flavornet.org

221 (for columns with a similar stationary phase to ZB-5 ms). The relative contribution (peak

222 area percentage) of each compound was calculated as a fraction of its integrated ion area

223 from total ion chromatograms (TIC) area (100\%).

\subsection{HPLC-DAD-ESI(+) MS Analysis}

There were introduced $10 \mu 1$ of previously filtered sample for injecting in HPLC system. For separation of phenolic compounds was used an Agilent 1200 HPLC system

(Mudura et al., 2018). The HPLC was fitted with an Eclipse XDB C18 column (150 x 4.6

mm x $5 \mu \mathrm{m}$ from Agilent Technologies, CA, USA). The column temperature was kept at

$25^{\circ} \mathrm{C}$. The compounds were separated by using a gradient mobile phase which consisted of

233 [water: $0.1 \%$ acetic acid in acetonitrile (99:1)] (solvent A) and [0.1\% acetic acid in

234 acetonitrile] (solvent B). The gradient applied was as follows: A:B @ 95:5\% (v/v) (min 0-2),

235 from $95: 5 \%$ to $60: 40 \%(\mathrm{v} / \mathrm{v})(\min 2-18)$, from $60: 40 \%$ to $10: 90 \%(\mathrm{v} / \mathrm{v})(\min 18-20)$, then

236 isocratic for $4 \mathrm{~min}$ at 10:90\% (v/v) before decreasing from 10:90\% to $95: 5 \%(\mathrm{v} / \mathrm{v})(\min 24-$

237 25), at a flow rate of $0.5 \mathrm{ml} / \mathrm{min}$. For the semiquantitative analysis the compounds were

238 monitored at $280 \mathrm{~nm}$, based on gallic acid calibration curve $\left(\mathrm{R}^{2}=0.999\right)$ the phenolic

239 compounds were calculated and expressed as $\mathrm{mg}$ gallic acid equivalents (GAE)/L.

240 Qualitative identification was carried out using MS fragmentation employing an ESI (+) 
241 ionization model under the following conditions: $3000 \mathrm{~V}$ capillary voltage, at $300^{\circ} \mathrm{C}$, and

242 nitrogen flow $8 \mathrm{~L} / \mathrm{min}, \mathrm{m} / z: 100-1000$, full-scan. Two levels of energy were used to obtain 50

243 or 100 fragments in the range $m / z: 100-1000 \mathrm{Da}$.

\subsection{Statistical Analysis}

246 Data are reported as means \pm standard deviation (SD) for triplicate determinations. The

247 ANOVA analysis of variance was used to compare the mean values, using SPSS 19.0

248 statistical analysis (IBM, New York, USA) and Tukey’s Honestly Significant Differences

249 (HSD) test with a confidence interval of $95 \%$ or $99 \%$. A $p$-value below 0.05 was considered

250 statistically significant.

252 3. Results and Discussion

\subsection{Major volatile compounds in wood-aged apple brandy}

254 The most abundant major volatile in the apple brandy was methanol (at $\sim 1000 \mathrm{mg}$ per

$255100 \mathrm{~mL}$ alcohol), followed by ethyl-acetate (at $400 \mathrm{mg}$ per $100 \mathrm{~mL}$ ethanol) and 3-methyl-

256 1-butanol (at $\sim 180 \mathrm{mg}$ per $100 \mathrm{~mL}$ ethanol) (Table 1). Methanol is a typical volatile

257 compound present in many fruit brandies. The interest for this compound is focusing not only

258 the negative health related aspects (Levy, Hexdall, Gordon, Boeriu, Heller \& Nelson, 2003),

259 but also its contribution to fruit brandy authenticity (Coldea, Mudura \& Socaciu, 2017). The

260 presence of methanol in brandies can indicate the origin of raw material used (Coldea et al.,

261 2011). Apples are important sources of pectin ranging between 11.6-32.6 g/ $\mathrm{kg}$ fresh mass

262 (Rop, Jurikova, Sochor, Mlcek \& Kramarova, 2011), as such, among the fruit brandies, apple 
brandies can contain elevated levels of methanol due to the degradation of methoxylated

264 pectin when compared to other fruit brandies (Coldea et al., 2011), a fact also reinforced by

265 the (EC) No. 110/2008 Regulation of the European Parliament and of the Council. The

266 highest methanol content was recorded in fir wood aged brandy. In our experiments, while

267 there were statistically significant differences between the various samples with regards to

268 methanol, the variation within all wood-exposed samples was within $+1.5 \%$ of the control

269 which represents a negligible influence.

270 Higher alcohols, such as propanol, butanol, 2-butanol, 2-methyl-1-propanol, 2-methyl-

271 1-butanol and 3-methyl-1-butanol are formed as by-products of ethanolic fermentation, being

272 related to the yeast quality and to sugar and amino acids availability via Ehrlich pathway. In

273 specific proportions, they positively influence the aroma of distillates (Rodríguez-Solana,

274 Galego, Pérez-Santín \& Romano, 2018), however, when present in excess of $350 \mathrm{mg} / 100 \mathrm{~mL}$

275 AA higher alcohols are often indicative of poor quality distillates. Higher alcohols represent

276 a substantial part of the fusel oils, and their separation during distillation is strictly monitored,

277 even though fusel oils are not completely eliminated from the final spirit. Among the

278 identified higher alcohols, 3-methyl-1-butanol registered the highest content (Table 1), in

279 agreement with previous findings (Zhao, Xu, Li, Fan \& Jiang, 2009). Similar negligible

280 variations as seen with regards to methanol $( \pm 1.5 \%$ between the control and any of the wood-

281 exposed samples) were also observed for 1-propanol, 1-butanol, 2-methyl-1-propanol, 2-

282 methyl-1-butanol and 3-methyl-1-butanol. However, 2-butanol was present at markedly

283 higher levels (compared to the control) in all (but the pedunculate oak) samples (Table 1),

284 with a $>25 \%$ average increase. Cherry and mulberry wood caused a small, but significant, 
reduction in ethyl-acetate ( 2.5 and $3.5 \%$ respectively); whereas mulberry and walnut wood caused a small, but significant, reduction in acetaldehyde (3 and 2.5\% respectively). However, cherry wood caused a significant increase in acetaldehyde $(+37 \%)$. Most wood types (except sessile) caused a $>5 \%$ decrease in furfural; while cherry wood caused $\sim 15 \%$ decrease.

Ethyl-acetate is the most common ester in all alcoholic beverages (Cortés, Rodríguez, Salgado \& Domínguez, 2011). Our control brandy (non-wood) contained $409 \mathrm{mg} / 100 \mathrm{~mL}$ AA) ethyl-acetate, which was higher when compared to our previous study (Coldea et al., 2011) under similar conditions. The exposure to wood caused minor variations in the level of ethyl-acetate, with the greatest variations being sessile oak which caused a $2.3 \%$ increase, while mulberry wood caused a $3.5 \%$ decrease.

Acetaldehyde is a common fermentation product in yeast fermentations (Coldea et al., 2011; Vriesekoop, Barber \& Pamment, 2007). In a similar fashion to methanol and ethylacetate, acetaldehyde is an extremely volatile compound that occurs in the head fraction of the distillation, its content in the final distillate is strongly dependent of the separation applied during distillation (Mangas, Rodríguez, Moreno \& Blanco, 1996a). In this study we found higher values for acetaldehyde in comparison to our previous study on apple brandy (Coldea et al., 2011) and almost double when compared to earlier studies (Winterová, Mikulíková, Mazáč, \& Havelec, 2008). The ratio of acetaldehyde, ethyl acetate and amyl alcohols contribute greatly to the final flavour and quality of distillates (Apostolopoulou, Flouros, Demertzis \& Akrida-Demertzi, 2005). Compared to the non-wood control brandy (at 40.69 $\mathrm{mg} / 100 \mathrm{~mL} \mathrm{AA}$ ), the acetaldehyde content did not alter significantly following exposure to 
any of the woods, except for exposure to cherry wood which caused an increase by about $35 \%$ (Table 1). This marked increase in acetaldehyde is most likely due to the oxidative nature of cherry wood (Chinnici et al., 2015), which could have facilitated to oxidation of ethanol to acetaldehyde.

\subsection{Minor volatile compounds in wood-aged apple brandy}

The quality of fruit distillates is influenced by a multitude of factors, of which the main are the specie and the quality of raw material, the geographical origin, varietal source, processing procedure and the ageing method applied (Coldea et al., 2011; Coldea, Socaciu, Moldovan \& Mudura, 2014; Śliwińska, Wiśniewska, Dymerski, Wardencki, \& Namieśnik, 2015). The comparison of the minor volatile compounds of the wood-aged apple brandy in this study indicates a significant effect of the wood type used in the process (Table 2). All the minor volatile compounds identified in our study have in the past also been found in apple related products (Dimick, Hoskin \& Acree, 1983; Reis, Rocha, Barros, Delgadillo \& Coimbra, 2009).

Focussing on the non-wood-aged apple brandy, the minor volatiles were made up of terpenes, higher alcohols, esters, ketones and aldehydes, with the esters being the most abundant, representing more than $70 \%$ of all minor volatiles. As in previous studies, the esters of fatty acids had the highest contribution in the profile of brandies (Coldea et al., 2014; Rodríguez-Solana et al., 2018). We noted the absence of volatile organic acids in our apple brandy, which could be due to the efficiency of the reflux during distillation process. Volatile organic acids, known to make only a small contribution to brandy flavour (Coldea et al., 2014), remain in distillation residue, and only a small fraction passes through to the distillate, 
where in the presence of ethanol, much of the volatile organic acids are converted into esters (Bajer, Bajerová, Surmová, Kremr, Ventura \& Eisner, 2017).

In agreement with previous studies (Bajer et al., 2017; Coldea et al., 2014), ethyl esters represent the majority of aroma profile of apple brandy. The main ethyl esters contributors in our study were ethyl-acetate, ethyl isobutyrate, ethyl isovalerate, ethyl caproate, ethyl octanoate and ethyl decanoate, many of which are responsible for the fruity floral flavour (Zhao, Xu, Li, Fan, \& Jiang, 2009). These ethyl ester arise from the raw material (Dimick et al., 1983), through a range of metabolic activities during the fermentation process (the fatty acid esters of caproic, caprilic, capric and lauric acids), as a consequence of specific yeast strains, and through the yeast autolysis generated during the distillation process (Coldea et al., 2017; Rodríguez-Solana et al., 2018). Elevated temperatures $\left(25+^{\circ} \mathrm{C}\right)$ during the fermentation contribute to losses of esters due to volatilisation whereas low fermentation temperatures (the traditional fermentation process of fruit pomace usually takes place in the open air, within a wide range of temperatures $\left(5-25^{\circ} \mathrm{C}\right)$ promote the formation of short chain esters (Zhao et al., 2009).

Isobutyl-acetate, hexanal, ethyl-butyrate, ethyl-2-methyl-butyrate, ethyl-isovalerate, 1hexanol, 2-methylbutyal-isovalerate, hexyl-acetate, ethyl-caproate, hexyl-2methylbutanoate, and ethyl-nonanoate are known to be responsible for apple flavours (Dimick et al., 1983, Śliwińska et al., 2015). 1-Hexanol is also responsible for a grassy, herbaceous and fruity aroma to distillates (Rodríguez Solana et al., 2018; Śliwińska et al., 2015) and its abundance in fruit spirit depends on the freshness of raw material (Rodríguez Madrera \& Suárez Valles, 2007). Hexyl-2-methylbutanoate, is known for its green aroma in 
351 apple brandy (Śliwińska et al., 2015), and 2-methylbutyl-isovalerate a slightly green, but

352 heavy apple skin aroma, with hexyl acetate and ethyl caproate having found to significantly

353 contribute to the specific aroma of apple brandy (Śliwińska et al., 2015). Among the

354 compounds responsible apple flavour, the exposure to wood increased the concentration of

355 isobutyl-acetate, hexyl-2-methylbutanoate, and ethyl-nonaoate in all wood types with the

356 greatest increase in cherry wood for isobutyl-acetate and chestnut wood for both hexyl-2-

357 methylbutanoate, and ethyl-nonaoate. 1-hexanol, hexyl-acetate, and 2-methylbutyl-

358 isovalerate increased in all wood types (Table 2), except for 1-hexanol in cherry wood, 2-

359 methylbutyl-isovalerate in mulberry wood and hexyl-acetate in fir, cherry and walnut wood.

360 This data suggest that some apple-flavour associated compounds are being accentuated by

361 wood-ageing. However, ethyl-butyrate, ethyl-2-methylbutyrate, and ethyl-isovalerate were

362 substantially reduced in their relative concentrations in all wood types. Ethyl-caproate was

363 also reduced in most wood types, but only to a minor extend and a minor increase in cherry

364 wood. This data suggests that from additive effects with regards to wood exposure and spirit

365 ageing; wood also plays a subtractive role with regards to apple flavours in apple brandy.

366 Isoamyl-acetate, isobutyl-acetate, ethyl-caproate, 2-methylbutyl-acetate, ethyl-

367 octanoate, hexyl-2-methyl-butanoate, and ethyl-nonanoate all contribute to ripe banana

368 flavour (Dimick et al., 1983; Coldea et al., 2017); while 2-heptanone contributes a more

369 ketonic, unripe banana aroma. Among the minor volatile compounds, ethyl octanoate was

370 the major ester detected in our samples (Table 2), which contributes to sweet, floral, fruity,

371 banana, and apple/pear brandy aromas (Peinado, Moreno, Bueno, Moreno \& Mauricio,

372 2004). Almost all compounds that contribute to a banana flavour increase in relative 
concentration when exposed to any of the woods used in this study (Table 2). The only banana-related compound that decreased was ethyl-caproate in all wood-aged pălinca samples, except for cherry wood which caused an increase in ethyl-caproate.

The longer fatty acid esters such as: methyl-laurate, ethyl-laurate, and ethyltetradeconoate have all been associated with apple and contribute waxy and soapy sensations (Dimick et al., 1983; Coldea et al., 2017); while slightly shorter fatty acid esters such as ethyl octanoate and ethyl decanoate contribute less intense, oily flavours (Coldea et al., 2017). Of the longer fatty acid esters, only ethyl-laurate was present at a notable relative concentration (Table 2), which increased following the wood ageing period in all woods except for the mulberry wood where there was a minor decrease in ethyl-laurate.

We detected three terpenes in the control apple brandy sample (limonene, $\alpha$-farnescene, and $\alpha$-bergamotene), which have all previously been associated with apples (Reis et al., 2009), with $\alpha$-farnesene being specifically associated with apple skin (Huelin \& Murray, 1966), and with fruit brandies (Bajer et al., 2017). Terpenes are often, even at low olfactory thresholds, involved in the sensorial differentiation of beverages (Zhao et al., 2009). Limonene contributes to citrus and herbal aroma notes (Rodríguez-Solana et al., 2018; Śliwińska et al., 2015). The terpene with the greatest relative abundance was $\alpha$-farnescene, which entirely disappeared when exposed to both oaks, fir, and chestnut, and substantially disappeared in the remining woods. Limonene and $\alpha$-bergamotene were present in the control sample at a very low relative presence, of which $\alpha$-bergamotene entirely disappeared in all woods except for cherry wood. Limonene on the other hand did not substantially change 
394

395

396

when the brandy was exposed to wood except for sessile oak and mulberry where there were substantial increases.

\begin{abstract}
Acetaldehyde, benzaldehyde and nonanal were the main aldehydes found in the non-
\end{abstract} wood-aged brandies (Tables 1 and 2). Nonanal is known for its floral, fruity, green and woody aroma (Śliwińska et al., 2015). While benzaldehyde is a common natural constituent of stone fruit spirits (Bajer et al., 2017), it is also formed by the enzymatic hydrolysis of amygdalin found in the pips and was previously reported in apple brandy (Bajer et al., 2017). Benzaldehyde was substantially reduced following ageing on pendula oak, cherry, chestnut and fir oak wood, but increased somewhat when the brandy was aged in sessile oak, walnut and cherry wood. The increase in benzaldehyde during wood-ageing in cherry wood is in agreement with findings from De Rosso and coworkers (2009). Only minor, but statistically significant, changes were found in the apple brandy when aged in any of the wood types (Table 2). Interestingly, hexanal was not detected in the non-wood-aged spirit, however, both oak woods, fir, mulberry and walnut woods contained low levels of hexanal; while chestnut and cherry wood did not yield hexanal in the wood-aged brandy. This phenomenon, where minor volatile compounds were present in some wood-aged samples but not in the control samples includes: ethyl-pentanoate in cherry aged samples, isobutyl-caprylate in chestnut aged samples, ethyl(z)-4-decenoate, methyl-15-methylhexadecanoate and hexyl benzoate in fir aged samples (Table 2). This means that fir wood contributed four unique volatile compounds to the fir-aged brandies. 
The control (non-wood-aged) apple brandy contained a small number of phenolic compounds of which chlorogenic acid was the most abundant (Table 3). Chlorogenic acid is

418 a common contributor to the phenolic profile of in apple wine (Herrera Alvarez, Ferreira 419 Zielinski, Alberti, \& Nogueira, 2017; Tošović, Marković, Dimitrić Marković, Mojović \& 420 Milenković, 2017). Gallic acid and protocatechuic acid were present in the non-wood-aged 421 apple brandy at intermediate levels, while vanillic acid and syringic acid were present at trace 422 levels only. All wood types absorbed the traces of vanillic acid and syringic acid following 423 the ageing period, with the exception of chestnut wood where there was 56 -fold increase in 424 syringic acid. There were minor changes in the protocatechuic acid content, a distinctive 425 compound for apple brandies (Rusu Coldea, Socaciu, Fetea, Ranga \& Pârlog, 2011), in both 426 oak woods and chestnut wood, while the protochatechuic acid disappeared from all other 427 wood types following ageing (Table 3). Protocatechuic acid had the highest amount in 428 chestnut-aged samples $(3.32 \mathrm{mg} / \mathrm{L}$ GAE) which was significantly higher compared with 429 values reported elsewhere (Zhang et al., 2013).

Gallic acid is a compound considered as an oak wood ageing marker (Marques Bortoletto

431 \& Alcarde, 2015), is strongly related to the contact period in brandy (Spaho et al., 2019) and 432 the ageing technique applied (Rodríguez-Solana, Salgado, Domínguez \& Cortés-Diéguez, 433 2014). In this study, gallic acid substantially increased in both oak woods, cherry and chestnut 434 wood, but disappeared from all other wood types. The substantial presence of chlorogenic 435 acid in the control increased by about $80 \%$ after aging in mulberry wood, but was not 436 detectable in any of the other wood types. The two oak woods contributed roughly the same 437 phenolics, in similar concentrations, during the wood-ageing period. This study found gallic 
438

439

440 Rodríguez-Solana et al., 2014; Zhang et al., 2015). In this study, ferulic acid was present at

441 higher concentrations compared to previously published results (Rodríguez-Solana et al.,

442 2014). The higher occurrence of ferulic acid in our samples can be explained by its

443 sensitiveness to high toasting temperatures which were applied in Rodríguez-Solana and

444 coworkers' study (2014). The only main point of differentiation between the two oak woods

445 was that the sessile contributed protocatechuic aldehyde, which was not detected in the

446 pedunculate aged samples. Overall, sessile oak, pedunculate oak, fir, chestnut, cherry,

447 mulberry, and walnut woods contributed $11,12,7,14,9,8$, and 5 phenolic compounds

448 respectively, with a total quantity of $53,53,163,103,213,141$, and $55 \mathrm{mg} / \mathrm{L}$ GAE

449 respectively. Among the phenolic identified in our study, there was not a single phenolic

450 compound that was present in all wood types. However, almost all wood types contributed

451 p-hydroxybenzoic acid and vanillin, except for walnut wood and cherry wood which did not

452 contribute one of these compounds (Table 3). Vanillin, responsible for taste, aroma and

453 flavour of brandies aged in oak wood, is a marker of wood ageing (Rodríguez-Solana et al.,

454 2017). For a greater vanillin yield it is recommended to use a greater wood surface area

455 exposure (Rodríguez-Solana et al., 2014). Both benzoic aldehydes (vanillin and

456 syringaldehyde) were present in most wood aged samples, which is in agreement with

457 previous studies (Table 4) in barrel aged distillates (Rodríguez-Solana et al., 2014).

458 Syringaldehyde was not detected in untoasted cherry wood, but has been shown to be

459 associated with toasting of wood (Cabrita et al., 2011; Sanz et al., 2010a; Sanz et al., 2010b). 
460 Similar to our findings, substantial amounts of syringaldehyde were reported previously in 461 untoasted oak and chestnut exposed samples (De Rosso et al., 2009). It has been argued that 462 vanillin is only formed in cherry wood following a heat treatment (Sanz et al., 2010a), which 463 supports our data in that we did not detect any vanillin in our cherry wood exposed samples.

464 In our samples, vanillin was present at considerable levels in chestnut, walnut and fir exposed 465 apple brandies, which is almost twice the amount compared to the oak-exposed brandies 466 (Table 3). Protocatechuic aldehyde has previously been reported in unseasoned cherry and 467 chestnut woods (Sanz et al., 2010a; Sanz et al., 2010b), and not detected in oak barrel aged 468 distillates (Rodríguez-Solana et al., 2014). In this study, protocatechuic aldehyde was 469 detected in sessile, cherry and chestnut wood aged samples, with significantly higher 470 quantities in cherry wood aged samples (32.27 mg/L GAE). Furthermore, apart from both 471 oak woods, all other woods contributed catechin. Catechin was present most abundantly in 472 cherry wood exposed brandy at almost $19 \mathrm{mg} / \mathrm{L}$ GAE, more than twice the next highest level 473 of catechin detected (in chestnut matured samples). An association between high catechin 474 levels and cherry wood has previously been reported elsewhere (Sanz et al., 2010a), which 475 might indicate that catechin at elevated levels can be anticipated when spirits are matured in 476 cherry wood.

477 In the fir-aged samples we detected homovanilic acid, secoisolariciresinol, taxiresinol, 478 and at very substantial quantities, which we did not detect in any other wood type. The latter 479 three compounds however, are typical biomarkers for fir wood, and possess antioxidant, 480 antimicrobial and anti-inflammatory activities (Willför et al., 2003) and would impart a very 481 resiny flavour. However, despite the limited presence of homovanillic acid in our samples, it 
has previously been recorded in beverages matured in untoasted chestnut, oak and cherry wood in trace amounts (De Rosso et al., 2009). Walnut wood also yielded a number of phenolic compounds we did not detect in any other wood types, these were $p$-coumaric acid, rutin, and juglone. Juglone is well recognized for its antioxidant and antimicrobial activities and is considered a biomarker for walnut wood (Cosmulescu, Trandafir, Nour, Ionica, \& Tutulescu, 2014; Wianowska, Garbaczewska, Cieniecka-Roslonkiewicz, Dawidowicz \& Jankowska, 2016; Willför et al., 2003). Scopoletin is a compound commonly associated with oak aged spirits, and its relative presence has been shown to reflect the period of wood maturation (Otsuka \& Zenibayashi, 1974), as such scopoletin has previously been reported in oak and chestnut aged spirits (Alañón et al., 2011). In our samples, scopoletin was also found in both oak woods and chestnut with no significant differences between the oak and chestnut wood aged samples regarding scopoletin (Table 3). However, our data shows that scopoletin is also released from cherry wood, but not from mulberry, fir or walnut wood. Cherry wood was the most abundant source of scopoletin (13.03 mg/L GAE). Mulberry wood contributed dicaffeoylquinic acid as a unique phenolic compound at very high levels $(94.68 \pm 2.19 \mathrm{mg} / \mathrm{L}$ GAE). Cherry wood was the greatest contributor of phenolic compounds with most of the phenolic compounds making a substantial contribution each (10-58 mg/L GAE) to the wood-aged samples. Coniferaldehyde and protocatechuic aldehyde were previously found in considerable amounts in cherry wood extracts (Alañón et al., 2011), which agrees with our findings. The phenolic compounds quantified in this research might not represent high-doses, however, these compounds are of technological interest by 
503

504

505

506

507

508

509

510

511

512

513

514

515

516

517

518

519

520

521

potentially acting as authenticity markers for the type of wood used in the ageing of spirits

(Alañón et al., 2011; Rusu Coldea et al., 2011; Coldea et al., 2017).

Chestnut wood is a rich source of gallic acid and ellagitannins and is often chosen for beverage ageing especially due to its sensorial impact which includes a degree of bitterness and astringency (Puech, Prida \& Isz, 2007; Alañón et al., 2011; Zhang et al., 2015).

Hydroxybenzaldehyde, which is not dependent on the ageing period (Mangas, Rodríguez, Moreno, Suárez, \& Blanco, 1996b), was absent in the control brandy and remained absent in fir, cherry and walnut exposed brandies (Table 3). However, hydroxybenzaldehyde was found in high levels in chestnut wood exposed brandy at approximately twice the quantity compared to both oak types.

Sinapaldehyde was detected in both oaks, cherry and chestnut exposed brandies only, but absent in the control and mulberry, fir and walnut wood exposed brandies (Table 3). Similarly, coniferaldehyde was detected in both oaks, cherry, mulberry and chestnut exposed brandies only, but absent in the control and fir and walnut wood exposed brandies. Both coniferaldehyde and sinapaldehyde have been reported previously, at similar levels in oak matured apple brandies (Rodríguez-Solana et al., 2014). Cherry wood exposed apple brandies yielded the highest levels of both coniferaldehyde and sinapaldehyde in cherry wood exposed brandies, with $58.26 \mathrm{mg} / 1 \mathrm{GAE}, 45.76 \mathrm{mg} / 1 \mathrm{GAE}$, respectively, representing between 4 and 10-fold higher levels compared to any of the other woods that yielded these compounds. Both coniferaldehyde and sinapaldehyde were reported in seasoned and toasted chestnut and oak woods with a considerable increase following toasting (Cabrita et al., 2011; Sanz et al., 2010b). 
regarding the olive oil (Pedan, Popp, Rohn, Nyfeler \& Bongartz, 2019) but not for distilled

beverages. The sensorial impact of phenolic compounds in fruit brandies will be a subject of

further studies.

\section{Conclusions}

The results obtained in this study provide the first data on the phenolic and volatile

composition of the aged apple brandy (pălinca) in the presence of several wood species from

the Transylvania region in Romania and contribute to the knowledge about this alcoholic

beverage. The wood species considered were: two types of oak (Quercus petraea and

Quercus robur), plus sweet chestnut, mulberry, walnut, fir and cherry wood. Our results show

that rapid wood ageing of pălinca impacted both the volatile and phenolic profiles regardless

537 of the wood types employed.

538 Most major volatile compounds were not affected when aged in the presence of wood,

541 terpenes, higher alcohols, esters, ketones and aldehydes, with esters of fatty acids the main

542 contributors to volatile profile of pălinca, representing more than $70 \%$ of all minor volatiles.

543 The main esters contributors that increased in concentration were ethyl-acetate, isobutyl-

544 acetate, isoamyl-2-methylbutyrate, ethyl-benzoate, ethyl-nonanoate, methyl-deconoate,

545 ethyl-decenoate and ethyl-docecanoate, with mulberry, chestnut and cherry being the major

546 positive affectors. Some apple-flavor associated compounds, such as isobutyl-acetate, hexyl- 
547 2-methylbutanoate and ethyl-nonaoate, were accentuated by wood ageing. On the other hand

548 the main esters that decreased in concentration were ethyl-isobutyrate, ethyl-isovalerate, and

549 iso-butyrate, with fir and walnut being the major negative affectors.

550 Fir wood contributed the largest number of compounds, not found in the control. These

551 include hexanal, ethyl-4-decenoate, homovanilic acid, secoisolariciresinol, and taxiresinol.

552 The latter three phenolic compounds would impart a very resiny flavour to pălinca. The most

553 important source of catechin was cherry wood. Rutin and juglone were solubilised only in

554 walnut wood aged pălinca. Vanillin, increased significantly in chestnut aged apple brandy.

555 Gallic acid increased in both oak, cherry and chestnut wood aged apple brandies, and were

556 not found in other wood types.

557 Given the short ageing period analysed, these results revealed important indicators about 558 the alternative wood types used in wood-ageing of pălinca, but more so the inclusion of wood 559 inside bottled apple brandy. Considering the cost and labour insensitivity in handling wooden 560 barrels, the choice of a range wooden chips could potentially guide actors in the beverage 561 industry to viable alternatives. 


\section{Funding}

This research did not receive any specific grant from funding agencies in the public, commercial, or not-for-profit sectors.

\section{Acknowledgments}

We are grateful for the administrative support received from the University of Agricultural Sciences and Veterinary Medicine Cluj-Napoca, Romania. The authors wish to thank Mrs. Alina Vîlcan (University of Agricultural Sciences and Veterinary Medicine ClujNapoca, Romania) for skilful assistance in selection of wood species used in this study.

Conflicts of Interest: The authors declare no conflict of interest.

\section{References}

Alañón, M. E., Castro-Vázquez, L., Díaz-Maroto, M. C., Hermosín-Gutiérrez, I., Gordon, M. H., \& Pérez-Coello, M. S. (2011). Antioxidant capacity and phenolic composition of different woods used in cooperage. Food Chemistry, 129, 1584-1590. https://doi.org/10.1016/j.foodchem.2011.06.013.

Apostolopoulou, A. A., Flouros, A. I., Demertzis, P. G., \& Akrida-Demertzi, K. (2005). Differences in concentration of principal volatile constituents in traditional Greek distillates. Food Control, 16, 157-164. https://doi.org/10.1016/j.foodcont.2004.01.005.

Bajer, T., Bajerová, P., Surmová, S., Kremr, D., Ventura, K., \& Eisner, A. (2017). Chemical profiling of volatile compounds of various home-made fruit spirits using headspace solid-phase microextraction. Journal of the Institute of Brewing, 123, 105-112. https://doi.org/10.1002/jib.386. 
587 Cabrita, M. J., Barrocas Dias, C., \& Costa Freitas, A. M. (2011). Phenolic acids, phenolic 588 aldehydes and furanic derivatives in oak chips: American vs. French oaks. South African 589 Journal for Enology and Viticulture, 32, 204-210. https://doi.org/10.21548/32-2-1380.

590 Caldeira, I., Pereira, R., Clímaco, M. C., Belchior, A. P., \& De Sousa, R. B. (2004). Improved 591 method for extraction of aroma compounds in aged brandies and aqueous alcoholic wood 592 extracts using ultrasound. Analytica Chimica Acta, 513, 125-134. 593 https://doi.org/10.1016/j.aca.2003.10.011.

594 Canas, S., Caldeira, I., Anjos, O., Lino, J., Soares, A. \& Belchior, A. P. (2016). 595 Physicochemical and sensory evaluation of wine brandies aged using oak and chestnut 596 wood simultaneously in wooden barrels and in stainless steel tanks with staves. 597 International Journal of Food Science and Technology, 51, 2537-2545. $598 \quad$ https://doi.org/10.1111/ijfs.13235.

599 Chinnici, F., Natali, N., Bellachioma, A., Versari, A., \& Riponi, C. (2015). Changes in 600 phenolic composition of red wines aged in cherry wood. LWT - Food Science and 601 Technology, 60, 977-984. https://doi.org/10.1016/j.lwt.2014.10.029.

602 Cîrstea, S. D., Moldovan-Teselios, C., Cîrstea, A., Turcu, A. C., \& Darab, C. P. (2018). 603 Evaluating renewable energy sustainability by composite index. Sustainability, 10. 604 https://doi.org/10.3390/su10030811.

605 Coldea, T. E., Mudura, E., \& Socaciu, C. (2017). Advances in distilled beverages authenticity 606 and quality testing. In M. T. Stauffer (Ed.), Ideas and applications toward sample 607 preparation for food and beverage analysis (pp. 109-130). London: IntechOpen.

608 Coldea, T. E., Socaciu, C., Moldovan, Z., \& Mudura, E. (2014). Minor volatile compounds 609 in traditional homemade fruit brandies from Transylvania-Romania, as determined by 610 GC-MS analysis. Notulae Botanicae Horti Agrobotanici, 42, 530-537. $611 \quad$ https://doi.org/10.15835/nbha4229607. 
612 Coldea, T. E., Socaciu, C., Pârv, M., \& Vodnar, D. (2011). Gas-chromatographic analysis of 613 major volatile compounds found in traditional fruit brandies from Transylvania, 614 Romania. Notulae Botanicae Horti Agrobotanici, 39, 109-116. 615 https://doi.org/10.15835/nbha3926053.

616 Cortés, S., Rodríguez, R., Salgado, J. M., \& Domínguez, J. M. (2011). Comparative study 617 between Italian and Spanish grape marc spirits in terms of major volatile compounds. 618 Food Control, 22, 673-680. https://doi.org/10.1016/j.foodcont.2010.09.006.

619 Cosmulescu, S., Trandafir, I., Nour, V., Ionica, M., \& Tutulescu, F. (2014). Phenolics 620 content, antioxidant activity and color of green walnut extracts for preparing walnut 621 622 liquor. Notulae Botanicae Horti Agrobotanici, 42, 551-555. https://doi.org/10.15835/nbha4229649.

De Rosso, M., Cancian, D., Panighel, A., Vedova, A. D., \& Flamini, R. (2009). Chemical compounds released from five different woods used to make barrels for aging wines and spirits: volatile compounds and polyphenols. Wood Science and Technology, 43, 375385. https://doi.org/10.1007/s00226-008-0211-8.

Delgado-González, M. J., Sánchez-Guillén, M. M., García-Moreno, M. V., RodríguezDodero, M. C., García-Barroso, C., \& Guillén-Sánchez, D. A. (2017). Study of a laboratory-scaled new method for the accelerated continuous ageing of wine spirits by applying ultrasound energy. Ultrasonics Sonochemistry, 36, 226-235. https://doi.org/10.1016/j.ultsonch.2016.11.031.

Dimick, P. S., Hoskin, J. C., \& Acree, T. E. (1983). Review of apple flavor-state of the art. Critical Reviews in Food Science \& Nutrition, 18, 387-409. https://doi.org/10.1080/10408398309527367.

635 Diouf, P. N., Merlin, A., \& Perrin, D. (2006). Antioxidant properties of wood extracts and 636 colour stability of woods. Annals of Forest Science, 63, 525-534. 637 https://doi.org/10.1051/forest:2006035. 
638 Dippong, T., Avram, A., \& Mihali, C. (2019). Gas chromatography assessments of the major 639 volatile compounds in traditional fruit brandies throughout fruit and wood maturation.

640

641

642 Studia Universitatis Babes-Bolyai, Chemia, 64, 141-155. DOI:10.24193/subbchem.2019.4.11.

Fan, W., Xu, Y., Yu, A. (2006). Influence of oak chips geographical origin, toast level, dosage and aging time on volatile compounds of apple cider. Journal of the Institute of Brewing, 112, 255-263. https://doi.org/10.1002/j.2050-0416.2006.tb00721.x.

Herrera Alvarez. L. V., Ferreira Zielinski, A. A., Alberti, A., \& Nogueira, A. (2017). Monitoring of the phenolic compounds and in vitro antioxidant activity of apple beverages according to geographical origin and their type: a chemometric study. $L W T$ Food Science and Technology, 84, 385-393. https://doi.org/10.1016/j.1wt.2017.05.078.

Huelin, F. E., \& Murray, K. E. (1966). $\alpha$-Farnesene in the natural coating of apples. Nature, 210, 1260-1261. https://doi.org/10.1038/2101260a0.

Levy, P., Hexdall, A., Gordon, P., Boeriu, C., Heller, M., \& Nelson, L. (2003). Methanol contamination of Romanian home-distilled alcohol. Journal of Toxicology: Clinical Toxicology, 41, 23-28. https://doi.org/10.1081/CLT-120018267.

Liu X. Y., Timar, M. C., Varodi, A. M., \& Sawyer, G. (2017). An investigation of accelerated temperature-induced ageing of four wood species: colour and FTIR. Wood Science and Technology, 51, 357-378. https://doi.org/10.1007/s00226-016-0867-4.

Magalhães, P. J., Almeida, S. M., Carvalho, A. M., Gonçalves, L. M., Pacheco, J. G., Cruz, J. M., Guido, L. F., \& Barros, A. A. (2011). Influence of malt on the xanthohumol and isoxanthohumol behavior in pale and dark beers: a micro-scale approach. Food Research International, 44, 351-359. https://doi.org/10.1016/j.foodres.2010.10.008.

Mangas, J., Rodríguez, R., Moreno, J., Suárez, B., \& Blanco, D. (1996a). Changes in the major volatile compounds of cider distillates during maturation. LWT - Food Science and Technology, 29, 357-364. https://doi.org/10.1006/fstl.1996.0054. 
664 Mangas, J., Rodríguez, R., Moreno, J., Suárez, B., \& Blanco, D. (1996b). Evolution of 665 aromatic and furanic congeners in the maturation of cider brandy: a contribution to its 666 characterization. Journal of Agricultural and Food Chemistry, 44, 3303-3307. 667 https://doi.org/10.1021/jf950782t.

668 Marques Bortoletto, A., \& Alcarde, A. R. (2015). Aging marker profile in cachaça is 669 influenced by toasted oak chips. Journal of the Institute of Brewing, 121, 70-77. 670 https://doi.org/10.1002/jib.202.

671 Marques Bortoletto, A., Casagrande Silvello, G., \& André Ricardo Alcarde, A. R. (2018). 672 Good Manufacturing Practices, Hazard Analysis and Critical Control Point plan proposal 673 for distilleries of cachaça. Scientia Agricola (Piracicaba, Braz.), 75, 432-443. $674 \quad$ http://dx.doi.org/10.1590/1678-992x-2017-0040.

675 Martínez-Gil, A., del Alamo-Sanza, M., Sánchez-Gómez, R., \& Nevares, I. (2018). Different 676 Woods in Cooperage for Oenology: A Review. Beverages, 4, 94. 677 https://doi.org/10.3390/beverages4040094.

678 Monakhova, Y. B., \& Lachenmeier, D. W. (2012). The Margin of Exposure of 5679 Hydroxymethylfurfural (HMF) in Alcoholic Beverages. Environmental Health and 680 Toxicology, 27, e2012016. https://doi.org/10.5620/eht.2012.27.e2012016.

681 Mudura, E., Coldea, T. E., Socaciu, C., Ranga, F., Pop, C. R., Rotar, A. M., \& Pasqualone, 682 A. (2018). Brown beer vinegar: a potentially functional product based on its phenolic 683 profile and antioxidant activity. Journal of the Serbian Chemistry Society, 83, 19-30. 684 https://doi.org/10.2298/JSC170803107M.

685 Otsuka, K. I., \& Zenibayashi, Y. (1974). On the determination of scopoletin in aged distilled 686 liquors. Agricultural and Biological Chemistry, 38, 1079-1080. 687 https://doi.org/10.1080/00021369.1974.10861285. 
688 Parisi, S., \& Luo, W. (2018). Maillard reaction in processed foods - reaction mechanisms.

689 In: Chemistry of Maillard reactions in processed foods. Pg 39-51. Springer, Cham. $690 \quad$ https://doi.org/10.1007/978-3-319-95463-9_2.

691 Pedan, V., Popp, M., Rohn, S., Nyfeler, M., \& Bongartz, A. (2019). Characterization of 692 phenolic compounds and their contribution to sensory properties of olive oil. Molecules, $69324,20-41$. https://doi.org/10.3390/molecules24112041.

694 Peinado, R. A., Moreno, J., Bueno, J. E., Moreno, J. A., \& Mauricio, J. C. (2004). 695 Comparative study of aromatic compounds in two young white wines subjected to pre696 fermentative cryomaceration. Food Chemistry, 84, 585-590. 697 https://doi.org/10.1016/S0308-8146(03)00282-6.

698 Puech, J., Prida, A., \& Isz, S. (2007). Quality assessment of oenological tannins utilising 699 global selectivity chemical sensors array ("Electronic Tongue"). South African Journal 700 for Enology and Viticulture, 28, 101-106. https://doi.org/10.21548/28-2-1465.

701 Regulation (EC) No 110/2008 of the European Parliament and of the Council of 15 January 7022008 on the Definition, Description, Presentation, Labelling and the Protection of 703 Geographical Indications of Spirit Drinks and Repealing Council Regulation (EEC) No 704 1576/89; Official Journal of the European Union: Luxembourg, 2008; p. L 39/32.

705 Reis, S. F., Rocha, S. M., Barros, A. S., Delgadillo, I., \& Coimbra, M. A. (2009). 706 Establishment of the volatile profile of 'Bravo de Esmolfe'apple variety and 707 identification of varietal markers. Food Chemistry, 113, 513-521. $708 \quad$ https://doi.org/10.1016/j.foodchem.2008.07.093.

709 Rodríguez Madrera, R., \& Suárez Valles, B. (2007). Determination of volatile compounds in 710 cider spirits by gas chromatography with direct injection. Journal of Chromatographic $711 \quad$ Science, 45, 428-434. https://doi.org/10.1093/chromsci/45.7.428. 
712 Rodríguez Madrera, R., Gomis, D. B., \& Mangas Alonso, J. J. (2003). Influence of distillation 713 system, oak wood type, and aging time on volatile compounds of cider brandy. Journal 714 of Agricultural and Food Chemistry, 51, 5709-5714. https://doi.org/10.1021/jf034280o. 715 Rodríguez Madrera, R., Suárez Valles, B., \& Picinelli Lobo, A. (2011). Chemical and sensory 716 changes in fresh cider spirits during maturation in inert containers. Journal of the Science 717 of Food and Agriculture, 91, 797-804. https://doi.org/10.1002/jsfa.4249.

718 Rodríguez Madrera, R., Suárez Valles, B., Diñeiro García, Y., Del Valle Argüelles, P., \& 719 Picinelli Lobo, A. (2010). Alternative woods for aging distillates - an insight into their 720 phenolic profiles and antioxidant activities. Food Science and Biotechnology, 19, 11291134. https://doi.org/10.1007/s10068-010-0161-4.

Rodríguez-Solana, R., Galego, L. R., Pérez-Santín, E., \& Romano, A. (2018). Production method and varietal source influence the volatile profiles of spirits prepared from fig fruits (Ficus carica L.). European Food Research and Technology, 244, 2213-2229. https://doi.org/10.1007/s00217-018-3131-3.

Rodríguez-Solana, R., Rodríguez-Freigedo, S., Salgado, J. M., Domínguez, J. M., \& CortésDiéguez, S. (2017). Optimisation of accelerated ageing of grape marc distillate on a micro-scale process using a Box-Benhken design: influence of oak origin, fragment size and toast level on the composition of the final product. Australian Journal of Grape and Wine Research, 23, 5-14. https://doi.org/10.1111/ajgw.12249.

Rodríguez-Solana, R., Salgado, J. M., Domínguez, J. M., \& Cortés-Diéguez, S. (2014). First approach to the analytical characterization of barrel-aged grape marc distillates using phenolic compounds and colour parameters. Food Technology and Biotechnology, 52, 391-402. https://doi.org/10.17113/ftb.52.04.14.3627.

Rop, O., Jurikova, T., Sochor, J., Mlcek, J., \& Kramarova, D. (2011). Antioxidant capacity, scavenging radical activity and selected chemical composition of native apple cultivars 
from Central Europe. Journal of Food Quality, 34, 187-194. https://doi.org/10.1111/j.1745-4557.2011.00387.x.

Rusu Coldea, T. E., Socaciu, C., Fetea, F., Ranga, F., \& Pârlog, R. (2011). Phenolic derivatives as authenticity markers of traditional homemade brandies from different counties of Transylvania, using UV-VIS and HPLC analysis. Bulletin UASVM Agriculture, 68, 518-528. http://dx.doi.org/10.15835/buasvmen-agr:6610.

Salanţă, L. C., Tofană, M., Pop, C., Pop, A., Coldea, T., \& Mudura, E. (2017). Beverage alcohol choice among university students: perception, consumption and preferences. BUASVM Food Science and Technology, 74, 23-30. https://doi.org/10.15835/buasvmcnfst:12633.

Sanz, M., Cadahía, E., Esteruelas, E., Muñoz, A. M., Fernández de Simón, B., Hernández, T., \& Estrella, I. (2010a). Phenolic compounds in cherry (Prunus avium) heartwood with a view to their use in cooperage. Journal of Agricultural and Food Chemistry, 58, 49074914. https://doi.org/10.1021/jf100236v.

Sanz, M., Cadahía, E., Esteruelas, E., Muñoz, A. M., Fernández de Simón, B., Hernández, T., \& Estrella, I. (2010b). Phenolic compounds in chestnut (Castanea sativa Mill.) heartwood. Effect of toasting at cooperage. Journal of Agricultural and Food Chemistry, 58, 9631-9640. https://doi.org/10.1021/jf102718t.

Schahinger, G., \& Rankine, B. C. (2005). Cooperage for winemakers. Winetitles, Ashford, Australia.

Singleton, V. L. (1995). Maturation of wines and spirits: comparisons, facts, and hypotheses. American Journal of Enology and Viticulture, 46(1), 98-115.

Śliwińska, M., Wiśniewska, P., Dymerski, T., Wardencki, W., \& Namieśnik, J. (2015). The flavour of fruit spirits and fruit liqueurs: a review. Flavour and Fragrance Journal, 30, 197-207. https://doi.org/10.1002/ffj.3237. 
762 Socaci, S. A., Socaciu, C., Mureşan, C., Fărcaş, A., Tofană, M., Vicaş, S., \& Pintea, A. 763 (2014). Chemometric discrimination of different tomato cultivars based on their volatile 764 fingerprint in relation to lycopene and total phenolics content. Phytochemical Analysis, $765 \quad 25,161-169$. https://doi.org/10.1002/pca.2483.

766 Spaho, N., Đukic-Ratković, D., Nikićević, N., Blesić, M., Tešević, V., Mijatović, B., \& 767 Smajić Murtić, M. (2019). Aroma compounds in barrel aged apple distillates from two 768 different distillation techniques. Journal of the Institute of Brewing, 125, 389-397. 769 https://doi.org/10.1002/jib.573.

770 Tao, Y., Zhang, Z., \& Sun, D. W. (2014). Experimental and modeling studies of ultrasound771 assisted release of phenolics from oak chips into model wine. Ultrasonics 772 Sonochemistry, 21, 1839-1848. https://doi.org/10.1016/j.ultsonch.2014.03.016.

773 Tchabo, W., Ma, Y., Kwaw, E., Zhang, H., Xiao, L., \& Tahir, H. E. (2017). Aroma profile 774 and sensory characteristics of a sulfur dioxide-free mulberry (Morus nigra) wine 775 subjected to non-thermal accelerating aging techniques. Food Chemistry, 232, 89-97. 776 https://doi.org/10.1016/j.foodchem.2017.03.160.

777 Tošović, J., Marković, S., Dimitrić Marković, J. M., Mojović, M., \& Milenković, D. (2017).

778 Antioxidative mechanisms in chlorogenic acid. Food Chemistry, 237, 390-398. 779 https://doi.org/10.1016/j.foodchem.2017.05.080.

780 Vriesekoop, F., Barber, A. R., \& Pamment, N. B. (2007). Acetaldehyde mediates growth 781 stimulation of ethanol-stressed Saccharomyces cerevisiae: evidence of a redox-driven 782 mechanism. Biotechnology Letters, 29, 1099-1103. DOI:10.1007/s10529-007-9367-9.

783 Wianowska, D., Garbaczewska, S., Cieniecka-Roslonkiewicz, A., Dawidowicz, A. L., \& 784 Jankowska, A. (2016). Comparison of antifungal activity of extracts from different 785 Juglans regia cultivars and juglone. Microbial Pathogenesis, 100, 263-267. 786 https://doi.org/10.1016/j.micpath.2016.10.009. 
787 Willför, S. M., Ahotupa, M. O., Hemming, J. E., Reunanen, M. H., Eklund, P. C., Sjöholm,

788 R. E., Eckerman, C. S., Pohjamo, S. P., \& Holmbom, B. R. (2003). Antioxidant activity

789 of knotwood extractives and phenolic compounds of selected tree species. Journal of

790 Agricultural and Food Chemistry, 51, 7600-7606. https://doi.org/10.1021/jf030445h.

791 Winterová, R., Mikulíková, R., Mazáč, J., \& Havelec, P. (2008). Assessment of the

792 authenticity of fruit spirits by gas chromatography and stable isotope ratio analyses.

793 Czech Journal of Food Sciences, 26, 368-375. https://doi.org/10.17221/1610-CJFS.

794 Zhang, B., Cai, J., Duan, C. Q., Reeves, M. J., \& He, F. (2015)._A review of polyphenolics

795 in oak woods. International Journal of Molecular Sciences, 16, 6978-7014.

796 https://doi.org/10.3390/ijms16046978.

797 Zhang, B., Zeng, X. A., Sun, D. W., Yu, S. J., Yang, M. F., \& Ma, S. (2013). Effect of electric

798 field treatments on brandy aging in oak barrels. Food and Bioprocess Technology, 6,

799 1635-1643. https://doi.org/10.1016/j.ifset.2013.07.003.

800 Zhao, Y., Xu, Y., Li, J., Fan, W., \& Jiang, W. (2009). Profile of volatile compounds in 11

801 brandies by headspace solid-phase microextraction followed by gas chromatography-

802 mass spectrometry. Journal of Food Science, 74, 90-99. https://doi.org/10.1111/j.1750-

$803 \quad$ 3841.2008.01029.x.

804

805 
Table 1. Major volatile compounds of traditional Romanian apple brandy after rapid ageing with different wood chips (mg/100mL AA). Each analyse was carried out in triplicate.

808

\begin{tabular}{|c|c|c|c|c|c|c|c|c|}
\hline & Control & Pedunculate oak & Fir & Chestnut & Cherry & Mulberry & Sessile oak & Walnut \\
\hline Acetaldehyde & $40.69 \pm 0.54^{b}$ & $40.44 \pm 0.71^{\mathrm{b}}$ & $40.67 \pm 1.02^{b}$ & $39.77 \pm 0.39^{b}$ & $55.74 \pm 0.09^{\mathrm{a}}$ & $39.44 \pm 0.45^{b}$ & $40.91 \pm 0.49^{b}$ & $39.61 \pm 0.34^{b}$ \\
\hline Ethyl acetate & $409.16 \pm 0.26^{\mathrm{d}}$ & $417.25 \pm 0.30^{b}$ & $416.10 \pm 0.15^{c}$ & $417.28 \pm 0.12^{\mathrm{b}}$ & $397.45 \pm 0.15^{\mathrm{f}}$ & $394.85 \pm 0.65^{\mathrm{g}}$ & $418.66 \pm 0.10^{\mathrm{a}}$ & $403.25 \pm 0.45^{\mathrm{e}}$ \\
\hline Methanol & $1050.38 \pm 1.93^{\mathrm{d}}$ & $1062.22 \pm 1.23^{\mathrm{ab}}$ & $1066.59 \pm 1.66^{\mathrm{a}}$ & $1050.90 \pm 2.03^{\mathrm{d}}$ & $1051.22 \pm 1.19^{\mathrm{d}}$ & $1058.66 \pm 1.87^{b c}$ & $1056.70 \pm 1.92^{\mathrm{c}}$ & $1054.86 \pm 1.99^{\mathrm{cc}}$ \\
\hline 2-Butanol & $0.14 \pm 0.01 \mathrm{bc}$ & $0.14 \pm 0.02^{\mathrm{c}}$ & $0.19 \pm 0.01 \mathrm{ab}$ & $0.17 \pm 0.00^{\mathrm{abc}}$ & $0.17 \pm 0.01^{\mathrm{abc}}$ & $0.20 \pm 0.02^{\mathrm{a}}$ & $0.17 \pm 0.02^{\mathrm{abc}}$ & $0.16 \pm 0.00^{\mathrm{abc}}$ \\
\hline 1-Propanol & $27.97 \pm 0.30^{\mathrm{ab}}$ & $28.21 \pm 0.10^{\mathrm{a}}$ & $28.25 \pm 0.20^{\mathrm{a}}$ & $27.72 \pm 0.03^{b}$ & $27.87 \pm 0.12^{\mathrm{ab}}$ & $28.28 \pm 0.11^{\mathrm{a}}$ & $28.09 \pm 0.04^{\mathrm{ab}}$ & $27.94 \pm 0.06^{\mathrm{ab}}$ \\
\hline 2-Methyl-1-propanol & $70.40 \pm 0.02^{\mathrm{c}}$ & $71.00 \pm 0.05^{\mathrm{a}}$ & $71.01 \pm 0.00^{\mathrm{a}}$ & $69.98 \pm 0.03^{f}$ & $70.09 \pm 0.01^{\mathrm{e}}$ & $70.96 \pm 0.00^{\mathrm{a}}$ & $70.60 \pm 0.05^{b}$ & $70.24 \pm 0.00^{\mathrm{d}}$ \\
\hline 1-Butanol & $7.37 \pm 0.12^{\mathrm{ab}}$ & $7.42 \pm 0.06^{\mathrm{ab}}$ & $7.40 \pm 0.01^{\mathrm{ab}}$ & $7.29 \pm 0.00^{b}$ & $7.28 \pm 0.02^{b}$ & $7.43 \pm 0.00^{\mathrm{a}}$ & $7.34 \pm 0.00^{\mathrm{ab}}$ & $7.32 \pm 0.02^{a b}$ \\
\hline 2-Methyl-1-butanol & $49.16 \pm 0.04^{\mathrm{a}}$ & $49.19 \pm 0.14^{\mathrm{a}}$ & $49.23 \pm 0.19^{\mathrm{a}}$ & $48.07 \pm 0.09^{\mathrm{c}}$ & $48.56 \pm 0.11^{\mathrm{b}}$ & $49.30 \pm 0.04^{\mathrm{a}}$ & $48.69 \pm 0.10^{b}$ & $48.58 \pm 0.01^{b}$ \\
\hline 3-Methyl-1-butanol & $183.20 \pm 0.09^{c}$ & $184.40 \pm 0.01^{\mathrm{b}}$ & $184.41 \pm 0.02^{b}$ & $181.89 \pm 0.14^{\mathrm{f}}$ & $182.46 \pm 0.10^{\mathrm{e}}$ & $184.86 \pm 0.02^{\mathrm{a}}$ & $183.25 \pm 0.09^{\mathrm{c}}$ & $182.84 \pm 0.04^{\mathrm{d}}$ \\
\hline Furfural & $2.91 \pm 0.00^{\mathrm{ab}}$ & $2.76 \pm 0.03^{\mathrm{c}}$ & $2.74 \pm 0.09^{\mathrm{c}}$ & $2.76 \pm 0.08^{\mathrm{c}}$ & $2.52 \pm 0.01^{\mathrm{d}}$ & $2.82 \pm 0.00^{\mathrm{bc}}$ & $2.99 \pm 0.00^{\mathrm{a}}$ & $2.79 \pm 0.05^{\mathrm{bc}}$ \\
\hline
\end{tabular}


Table 2. Minor volatile compounds of traditional Romanian apple brandy after rapid ageing with different wood chips. Values are expressed as the

\begin{tabular}{lcccccccccc}
\hline & Control & Pedunculate oak & Fir & Chestnut & Cherry & Mulberry & Sessile oak & Walnut & Significant differences \\
\hline 3-Methyl-1-Butanol & $15.14 \pm 1.06$ & $9.39 \pm 0.81$ & $15.71 \pm 1.27$ & $15.17 \pm 0.93$ & $17.04 \pm 1.20$ & $18.54 \pm 0.99$ & $16.74 \pm 0.97$ & $16.35 \pm 0.63$ & $* * *$ \\
\hline 2-Methyl-1-Butanol & $5.60 \pm 0.32$ & $4.54 \pm 0.30$ & $5.17 \pm 0.20$ & $4.80 \pm 0.48$ & $5.97 \pm 0.38$ & $6.81 \pm 0.45$ & $6.01 \pm 0.26$ & $5.39 \pm 0.51$ & $* * *$ \\
\hline Ethyl Isobutyrate & $7.56 \pm 0.71$ & $4.01 \pm 0.55$ & $3.89 \pm 0.12$ & $3.87 \pm 0.38$ & $4.71 \pm 0.19$ & $4.34 \pm 0.31$ & $4.07 \pm 0.27$ & $3.93 \pm 0.32$ & $* * *$ \\
\hline Isobutyl Acetate & $0.54 \pm 0.12$ & $0.60 \pm 0.11$ & $0.65 \pm 0.20$ & $0.60 \pm 0.15$ & $0.70 \pm 0.15$ & $0.70 \pm 0.12$ & $0.61 \pm 0.02$ & $0.69 \pm 0.06$ & NS \\
\hline Methyl Isovalerate & $0.20 \pm 0.05$ & $0.09 \pm 0.03$ & $0.06 \pm 0.01$ & nd & $0.50 \pm 0.10$ & $0.09 \pm 0.02$ & $0.08 \pm 0.00$ & $0.05 \pm 0.02$ & $* * *$ \\
\hline Hexanal & nd & $0.17 \pm 0.04$ & $0.59 \pm 0.13$ & nd & nd & $0.29 \pm 0.12$ & $0.14 \pm 0.01$ & $0.13 \pm 0.01$ & $* * *$ \\
\hline Ethyl Butyrate & $0.68 \pm 0.12$ & $0.47 \pm 0.01$ & $0.59 \pm 0.05$ & $0.42 \pm 0.05$ & nd & $0.49 \pm 0.13$ & $0.47 \pm 0.04$ & $0.43 \pm 0.08$ & $* * *$ \\
\hline Ethyl 2-Methylbutyrate & $4.22 \pm 0.43$ & $3.16 \pm 0.20$ & $3.33 \pm 0.36$ & $3.68 \pm 0.24$ & $3.42 \pm 0.20$ & $3.17 \pm 0.25$ & $2.66 \pm 0.20$ & $3.38 \pm 0.10$ & $* * *$ \\
\hline Ethyl Isovalerate & $10.85 \pm 0.50$ & $5.73 \pm 0.28$ & $5.63 \pm 0.30$ & $4.96 \pm 0.19$ & $6.36 \pm 0.20$ & $5.79 \pm 0.39$ & $5.39 \pm 0.27$ & $5.44 \pm 0.24$ & $* * *$ \\
\hline 1-Hexanol & $1.80 \pm 0.25$ & $2.11 \pm 0.31$ & $1.95 \pm 0.20$ & $2.05 \pm 0.30$ & $1.78 \pm 0.17$ & $2.22 \pm 0.05$ & $2.12 \pm 0.20$ & $2.17 \pm 0.30$ & NS \\
\hline Isoamyl Acetate & $3.82 \pm 0.20$ & $4.93 \pm 0.09$ & $4.88 \pm 0.17$ & $4.80 \pm 0.10$ & $4.87 \pm 0.25$ & $4.67 \pm 0.21$ & $4.11 \pm 0.12$ & $4.87 \pm 0.25$ & $* * *$ \\
\hline 2-Methylbutyl Acetate & $0.48 \pm 0.10$ & $0.56 \pm 0.12$ & $0.56 \pm 0.09$ & $0.50 \pm 0.09$ & $0.61 \pm 0.10$ & $0.64 \pm 0.00$ & $0.59 \pm 0.02$ & $0.54 \pm 0.20$ & NS \\
\hline 2-Heptanone & $0.07 \pm 0.01$ & $0.10 \pm 0.05$ & $0.08 \pm 0.03$ & $0.10 \pm 0.06$ & $0.09 \pm 0.03$ & $0.13 \pm 0.02$ & $0.10 \pm 0.04$ & $0.08 \pm 0.01$ & NS \\
\hline
\end{tabular}




\begin{tabular}{|c|c|c|c|c|c|c|c|c|c|}
\hline Ethyl Pentanoate & nd & nd & nd & nd & $0.06 \pm 0.03$ & nd & nd & nd & - \\
\hline Methyl Hexanoate & $0.06 \pm 0.01$ & $0.09 \pm 0.03$ & nd & nd & nd & $0.02 \pm 0.01$ & $0.04 \pm 0.03$ & $0.14 \pm 0.01$ & NS \\
\hline Benzaldehyde & $0.56 \pm 0.03$ & $0.40 \pm 0.09$ & $0.21 \pm 0.08$ & $0.29 \pm 0.01$ & $0.43 \pm 0.06$ & $0.71 \pm 0.11$ & $0.64 \pm 0.10$ & $0.70 \pm 0.06$ & $* * *$ \\
\hline Ethyl Caproate & $8.83 \pm 0.37$ & $8.27 \pm 0.35$ & $7.94 \pm 0.31$ & $8.21 \pm 0.18$ & $9.53 \pm 0.11$ & $7.69 \pm 0.46$ & $7.63 \pm 0.41$ & $7.78 \pm 0.28$ & $* * *$ \\
\hline Iso-Butyl-2-Methylbutyrate & $0.10 \pm 0.01$ & nd & $0.14 \pm 0.01$ & $0.18 \pm 0.02$ & $0.06 \pm 0.01$ & $0.12 \pm 0.03$ & $0.15 \pm 0.00$ & nd & NS \\
\hline Hexyl Acetate & $0.60 \pm 0.19$ & $0.66 \pm 0.12$ & $0.49 \pm 0.07$ & $0.65 \pm 0.10$ & $0.47 \pm 0.16$ & $0.63 \pm 0.10$ & $0.65 \pm 0.05$ & $0.50 \pm 0.05$ & NS \\
\hline Limonene & $0.06 \pm 0.02$ & $0.07 \pm 0.01$ & $0.05 \pm 0.01$ & $0.07 \pm 0.02$ & $0.04 \pm 0.02$ & $0.11 \pm 0.03$ & $0.18 \pm 0.02$ & $0.05 \pm 0.01$ & $* * *$ \\
\hline 2-Methylbutyl Butyrate & $0.03 \pm 0.01$ & $0.04 \pm 0.02$ & nd & $0.04 \pm 0.03$ & nd & $0.02 \pm 0.01$ & nd & nd & NS \\
\hline 2-Nonanone & $0.06 \pm 0.01$ & $0.08 \pm 0.02$ & $0.04 \pm 0.01$ & $0.09 \pm 0.03$ & $0.04 \pm 0.03$ & $0.10 \pm 0.02$ & $0.12 \pm 0.01$ & $0.04 \pm 0.02$ & $* * *$ \\
\hline Ethyl Heptanoate & $0.08 \pm 0.02$ & nd & nd & nd & $0.13 \pm 0.02$ & nd & $0.09 \pm 0.03$ & nd & - \\
\hline Isoamyl 2-Methylbutyrate & $0.44 \pm 0.09$ & $0.61 \pm 0.10$ & $0.58 \pm 0.04$ & $0.62 \pm 0.10$ & $0.53 \pm 0.01$ & $0.51 \pm 0.20$ & $0.56 \pm 0.09$ & $0.61 \pm 0.10$ & NS \\
\hline 2-Methylbutyl Isovalerate & $0.29 \pm 0.04$ & $0.42 \pm 0.10$ & $0.42 \pm 0.12$ & $0.45 \pm 0.13$ & $0.36 \pm 0.09$ & $0.23 \pm 0.01$ & $0.38 \pm 0.02$ & $0.42 \pm 0.12$ & NS \\
\hline Nonanal & $0.52 \pm 0.11$ & $0.64 \pm 0.11$ & $0.58 \pm 0.07$ & $0.62 \pm 0.01$ & $0.51 \pm 0.08$ & $0.55 \pm 0.10$ & $0.69 \pm 0.09$ & $0.63 \pm 0.01$ & NS \\
\hline Isoamyl Isovalerate & $0.10 \pm 0.00$ & $0.05 \pm 0.01$ & $0.06 \pm 0.02$ & $0.06 \pm 0.01$ & nd & $0.04 \pm 0.01$ & nd & nd & NS \\
\hline Methyl Octanoate & $0.39 \pm 0.03$ & $0.61 \pm 0.10$ & $0.53 \pm 0.01$ & $0.40 \pm 0.06$ & $0.40 \pm 0.04$ & $0.37 \pm 0.01$ & $0.38 \pm 0.04$ & $0.52 \pm 0.02$ & $* * *$ \\
\hline Ethyl Benzoate & $0.43 \pm 0.03$ & $0.67 \pm 0.00$ & $0.54 \pm 0.03$ & $0.69 \pm 0.03$ & $0.67 \pm 0.04$ & $0.71 \pm 0.01$ & $0.78 \pm 0.02$ & $0.42 \pm 0.03$ & $* * *$ \\
\hline Ethyl Octanoate & $19.85 \pm 2.02$ & $26.11 \pm 1.14$ & $25.19 \pm 0.95$ & $23.30 \pm 0.70$ & $22.56 \pm 0.59$ & $22.02 \pm 0.63$ & $22.27 \pm 0.18$ & $22.53 \pm 0.40$ & $* * *$ \\
\hline
\end{tabular}




\begin{tabular}{|c|c|c|c|c|c|c|c|c|c|}
\hline Hexyl 2-Methylbutanoate & $4.89 \pm 0.20$ & $6.65 \pm 0.30$ & $6.20 \pm 0.13$ & $6.79 \pm 0.21$ & $5.15 \pm 0.30$ & $5.80 \pm 0.16$ & $6.55 \pm 0.18$ & $6.21 \pm 0.20$ & $* * *$ \\
\hline Isopentyl Hexanoate & $0.09 \pm 0.02$ & $0.10 \pm 0.01$ & $0.12 \pm 0.01$ & $0.13 \pm 0.02$ & $0.07 \pm 0.02$ & $0.14 \pm 0.01$ & $0.13 \pm 0.03$ & $0.14 \pm 0.03$ & $*$ \\
\hline n.i. & $0.14 \pm 0.03$ & $0.22 \pm 0.02$ & $0.23 \pm 0.02$ & $0.18 \pm 0.01$ & $0.12 \pm 0.02$ & $0.28 \pm 0.01$ & $0.33 \pm 0.02$ & $0.16 \pm 0.03$ & $* * *$ \\
\hline Ethyl Nonanoate & $0.13 \pm 0.02$ & $0.20 \pm 0.02$ & $0.20 \pm 0.01$ & $0.22 \pm 0.02$ & $0.16 \pm 0.02$ & $0.17 \pm 0.03$ & $0.21 \pm 0.03$ & $0.21 \pm 0.01$ & $* * *$ \\
\hline Methyl Decanoate & $0.21 \pm 0.03$ & $0.51 \pm 0.04$ & $0.33 \pm 0.04$ & $0.43 \pm 0.06$ & $0.29 \pm 0.03$ & $0.34 \pm 0.05$ & $0.38 \pm 0.04$ & $0.49 \pm 0.04$ & $* * *$ \\
\hline Isobutyl Caprylate & nd & nd & nd & $0.04 \pm 0.01$ & nd & nd & nd & nd & - \\
\hline Ethyl 9-Decenoate & $0.11 \pm 0.03$ & $0.18 \pm 0.03$ & nd & $0.19 \pm 0.03$ & $0.09 \pm 0.01$ & $0.13 \pm 0.02$ & $0.17 \pm 0.02$ & $0.16 \pm 0.03$ & $* * *$ \\
\hline Ethyl (Z)-4-Decenoate & nd & nd & $0.12 \pm 0.03$ & nd & nd & nd & nd & nd & - \\
\hline Ethyl Decanoate & $8.30 \pm 0.29$ & $14.90 \pm 0.40$ & $10.83 \pm 0.20$ & $12.89 \pm 0.18$ & $9.53 \pm 0.30$ & $9.61 \pm 0.17$ & $11.84 \pm 0.13$ & $12.54 \pm 0.48$ & $* * *$ \\
\hline Isopentyl Octanoate & $0.07 \pm 0.01$ & nd & $0.05 \pm 0.02$ & $0.12 \pm 0.02$ & nd & $0.06 \pm 0.01$ & $0.11 \pm 0.01$ & $0.09 \pm 0.02$ & NS \\
\hline Alpha-Bergamotene & $0.05 \pm 0.01$ & nd & nd & nd & $0.04 \pm 0.02$ & nd & nd & nd & - \\
\hline Alpha-Farnesene & $0.71 \pm 0.10$ & nd & nd & nd & $0.32 \pm 0.04$ & $0.01 \pm 0.00$ & nd & $0.04 \pm 0.01$ & NS \\
\hline Methyl Dodecanoate & $0.03 \pm 0.01$ & $0.05 \pm 0.01$ & nd & $0.05 \pm 0.01$ & $0.04 \pm 0.02$ & nd & $0.05 \pm 0.02$ & $0.04 \pm 0.01$ & NS \\
\hline Methyl 15-Methylhexadecanoate & nd & nd & $0.03 \pm 0.01$ & nd & nd & nd & nd & nd & - \\
\hline Hexyl Benzoate & nd & $0.02 \pm 0.01$ & $0.02 \pm 0.01$ & nd & nd & nd & nd & nd & - \\
\hline Ethyl Laurate & $1.82 \pm 0.10$ & $2.57 \pm 0.12$ & $1.94 \pm 0.19$ & $2.25 \pm 0.19$ & $2.26 \pm 0.21$ & $1.70 \pm 0.06$ & $2.52 \pm 0.11$ & $1.96 \pm 0.11$ & $* *$ \\
\hline Ethyl Tetradecanoate & $0.08 \pm 0.02$ & nd & $0.07 \pm 0.01$ & $0.08 \pm 0.02$ & $0.09 \pm 0.02$ & $0.05 \pm 0.01$ & $0.08 \pm 0.02$ & $0.06 \pm 0.01$ & NS \\
\hline
\end{tabular}

$817 n$-number of replications; nd - not detected; NS - not significant, $\mathrm{P}>0.05 ;$ * significant $\mathrm{P} \leq 0.05 ; * *$ very significant $\mathrm{P} \leq 0.01 ; * * *$ extremely significant $\mathrm{P} \leq 0.001$ 
Table 3. Concentration of phenolic compounds (mg/L GAE) in of different wood aged apple distillates $(n=3)$.

\begin{tabular}{|c|c|c|c|c|c|c|c|c|}
\hline & Control & Sessile oak & Mulberry & Pedunculate oak & Fir & Cherry & Walnut & Chestnut \\
\hline Hydroxybenzaldehyde & nd & $6.56 \pm 0.21^{\mathrm{b}}$ & $4.56 \pm 0.21^{\mathrm{c}}$ & $6.27 \pm 0.04^{b}$ & nd & nd & nd & $13.45 \pm 0.21^{\mathrm{a}}$ \\
\hline Gallic acid & $1.82 \pm 0.03^{\mathrm{e}}$ & $2.55 \pm 0.01^{\mathrm{c}}$ & nd & $3.95 \pm 0.2^{\mathrm{a}}$ & nd & $2.26 \pm 0.02^{\mathrm{d}}$ & nd & $3.72 \pm 0.01^{\mathrm{b}}$ \\
\hline Vanillic acid & $0.01 \pm 0.08^{\mathrm{a}}$ & nd & nd & nd & nd & nd & nd & nd \\
\hline Protocatechuic acid & $2.89 \pm 0.22^{\mathrm{b}}$ & $2.09 \pm 0.02^{\mathrm{d}}$ & nd & $2.37 \pm 0.05^{\mathrm{c}}$ & nd & nd & nd & $3.32 \pm 0.95^{\mathrm{a}}$ \\
\hline Syringic acid & $0.02 \pm 0.01^{\mathrm{b}}$ & nd & nd & nd & nd & nd & nd & $1.12 \pm 0.07^{\mathrm{a}}$ \\
\hline Chlorogenic acid & $10.27 \pm 0.16^{\mathrm{b}}$ & nd & $18.83 \pm 1.01^{\mathrm{a}}$ & nd & nd & nd & nd & nd \\
\hline Homovanilic acid & nd & nd & nd & nd & $15.93 \pm 0.51^{\mathrm{a}}$ & nd & nd & nd \\
\hline Catechin & nd & nd & $4.70 \pm 0.09^{d}$ & nd & $5.76 \pm 0.22^{\mathrm{c}}$ & $18.95 \pm 0.42^{\mathrm{a}}$ & $2.76 \pm 0.11^{\mathrm{e}}$ & $7.57 \pm 0.11^{\mathrm{b}}$ \\
\hline$p$-Hydroxybenzoic acid & nd & $6.32 \pm 0.61^{\mathrm{c}}$ & $3.96 \pm 0.13^{\mathrm{d}}$ & $7.11 \pm 0.95^{\mathrm{c}}$ & $4.85 \pm 0.65^{\mathrm{d}}$ & $10.33 \pm 0.89^{b}$ & nd & $14.11 \pm 0.05^{\mathrm{a}}$ \\
\hline Vanilin & nd & $2.91 \pm 0.21^{\mathrm{e}}$ & $3.62 \pm 0.05^{\mathrm{d}}$ & $3.01 \pm 0.06^{\mathrm{e}}$ & $5.44 \pm 0.02^{\mathrm{c}}$ & nd & $5.88 \pm 0.10^{\mathrm{b}}$ & $7.38 \pm 0.02^{\mathrm{a}}$ \\
\hline$p$-Coumaric acid & nd & nd & nd & nd & nd & nd & $3.69^{\mathrm{a}} \pm 0.03$ & nd \\
\hline Ellagic acid & nd & $3.28 \pm 0.14^{\mathrm{c}}$ & nd & $2.91 \pm 0.09^{\mathrm{c}}$ & nd & $11.48 \pm 0.31^{\mathrm{a}}$ & nd & $4.38 \pm 0.27^{b}$ \\
\hline Rutin & nd & nd & nd & nd & nd & nd & $8.90^{\mathrm{a}} \pm 0.006$ & nd \\
\hline Ferulic acid & nd & $2.51 \pm 0.22^{c}$ & nd & $2.17 \pm 0.01^{\mathrm{c}}$ & nd & $21.16 \pm 0.82^{a}$ & nd & $18.22 \pm 0.67^{b}$ \\
\hline
\end{tabular}




\begin{tabular}{|c|c|c|c|c|c|c|c|c|}
\hline Secoisolariciresinol & nd & nd & nd & nd & $38.95 \pm 0.96^{\mathrm{a}}$ & nd & nd & nd \\
\hline Juglone & nd & nd & nd & nd & nd & nd & $4.28 \pm 0.21^{\mathrm{a}}$ & nd \\
\hline Taxiresinol & nd & nd & nd & nd & $76.27 \pm 1.04^{\mathrm{a}}$ & nd & nd & nd \\
\hline Dicafeoilquinic acid & nd & nd & $94.68 \pm 2.19^{\mathrm{a}}$ & nd & nd & nd & nd & nd \\
\hline Protocatechuic aldehyde & nd & $2.32 \pm 0.00^{\mathrm{c}}$ & nd & nd & nd & $32.27 \pm 0.72^{\mathrm{a}}$ & nd & $4.53 \pm 0.01^{b}$ \\
\hline Scopoletin & nd & $5.98 \pm 0.29^{c}$ & nd & $6.86 \pm 0.04^{b}$ & nd & $13.03 \pm 0.01^{\mathrm{a}}$ & nd & $6.69 \pm 0.01^{b}$ \\
\hline Lariciresinol & nd & nd & nd & nd & $16.54 \pm 0.30^{\mathrm{a}}$ & nd & nd & nd \\
\hline Coniferaldehyde & nd & $8.02 \pm 0.83^{c}$ & $8.27 \pm 0.02^{\mathrm{c}}$ & $11.26 \pm 0.19^{b}$ & nd & $58.26 \pm 1.16^{\mathrm{a}}$ & nd & $11.02 \pm 0.07^{\mathrm{b}}$ \\
\hline Syringaldehyde & nd & $6.35 \pm 0.63^{a}$ & $2.40 \pm 0.01^{\mathrm{d}}$ & $5.44 \pm 0.12^{\mathrm{b}}$ & nd & nd & nd & $4.33 \pm 0.26^{\mathrm{c}}$ \\
\hline Sinapaldehyde & nd & $2.81 \pm 0.02^{b}$ & nd & $3.03 \pm 0.01^{\mathrm{b}}$ & nd & $45.76 \pm 0.66^{\mathrm{a}}$ & nd & $3.47 \pm 0.01^{\mathrm{b}}$ \\
\hline
\end{tabular}


Table 4. Literature sources regarding phenolic compounds identified in this study, which have been already detected in brandy and/or wood.

\begin{tabular}{|c|c|c|c|}
\hline Phenolic compound & Source & Concentration & References \\
\hline Catechin & Seasoned cherry wood & $30150 \mu \mathrm{g} / \mathrm{g}$ & Sanz et al., 2010a \\
\hline \multirow[t]{2}{*}{ Chlorogenic acid } & Apple wine & $14-24 \mathrm{mg} / \mathrm{L}$ & Herrera Alvarez et al., 2017 \\
\hline & Apple brandy & $5.4-14.4 \mathrm{mg} / \mathrm{L}$ & Rusu Coldea et al., 2011 \\
\hline \multirow[t]{6}{*}{ Coniferaldehyde } & Toasted cherry wood & $332.59 \mu \mathrm{g} / \mathrm{g}$ & Alañón et al., 2011 \\
\hline & Seasoned chestnut wood & $8.42 \mu \mathrm{g} / \mathrm{g}$ & Sanz et al., $2010 \mathrm{~b}$ \\
\hline & Toasted chestnut wood & $328.00 \mu \mathrm{g} / \mathrm{g}$ & Sanz et al., $2010 b$ \\
\hline & Seasoned oak wood & $9.3 \mu \mathrm{g} / \mathrm{g}$ & Cabrita et al., 2011 \\
\hline & Toasted oak wood & $297.7-953.2 \mu \mathrm{g} / \mathrm{g}$ & Cabrita et al., 2011 \\
\hline & Oak barrel aged brandy & $13500 \mathrm{mg} / \mathrm{L} \mu \mathrm{g} / \mathrm{g}$ & Rodríguez-Solana et al., 2014 \\
\hline Ferulic acid & Oak barrel aged distillates & $900 \mathrm{mg} / \mathrm{L}$ & Rodríguez-Solana et al., 2014 \\
\hline \multirow[t]{2}{*}{ Gallic acid } & Electric field treated oak barrels & $0.15-0.56 \mathrm{mg} / \mathrm{L}$ & Zhang et al., 2013 \\
\hline & Apple brandy & $79.1-176.3 \mathrm{mg} / \mathrm{L}$ & Rusu Coldea et al., 2011 \\
\hline \multirow[t]{2}{*}{ Homovanilic acid } & Untoasted chestnut and oak wood & $1-10 \mu \mathrm{g} / \mathrm{g}$ & De Rosso et al., 2009 \\
\hline & Untoasted cherry wood & $0.1-0.9 \mu \mathrm{g} / \mathrm{g}$ & De Rosso et al., 2009 \\
\hline Hydroxybenzaldehyde & Wood aged cider brandy & $0.49 \mathrm{mg} / \mathrm{L}$ & Mangas et al., 1996 \\
\hline$p$-Coumaric acid & Heat treated oak wood & $53.78 \mu \mathrm{g} / \mathrm{g}$ & Alañón et al., 2011 \\
\hline
\end{tabular}




\begin{tabular}{|c|c|c|c|}
\hline Phenolic compound & Source & Concentration & References \\
\hline & Sessile oak wood & $26.84 \mu \mathrm{g} / \mathrm{g}$ & Alañón et al., 2011 \\
\hline & Heat treated chestnut wood & $116.12 \mu \mathrm{g} / \mathrm{g}$ & Alañón et al., 2011 \\
\hline & Heat treated cherry wood & $7.11 \mu \mathrm{g} / \mathrm{g}$ & Alañón et al., 2011 \\
\hline \multirow[t]{4}{*}{ Protocatechuic acid } & Oak cooperage wood & $239.31 \mu \mathrm{g} / \mathrm{g}$ & Alañón et al., 2011 \\
\hline & Sessile cooperage wood & $178.17 \mu \mathrm{g} / \mathrm{g}$ & Alañón et al., 2011 \\
\hline & Apple brandy & $1.5-1.7 \mathrm{mg} / \mathrm{L}$ & Rusu Coldea et al., 2011 \\
\hline & Electric field treated oak barrels & $0.1 \mathrm{mg} / \mathrm{L}$ & Zhang et al., 2013 \\
\hline \multirow[t]{3}{*}{ Protocatechuic aldehyde } & Unseasoned cherry wood & $12.94 \mu \mathrm{g} / \mathrm{g}$ & Sanz et al., $2010 \mathrm{a}$ \\
\hline & Toasted chestnut wood & $7.90 \mu \mathrm{g} / \mathrm{g}$ & Sanz et al., 2010b \\
\hline & Toasted cherry wood & $26.92 \mu \mathrm{g} / \mathrm{g}$ & Alañón et al., 2011 \\
\hline Rutin & Walnut extract & $74.7 \mathrm{mg} \mathrm{GAE} / \mathrm{L}$ & Cosmulescu et al., 2014 \\
\hline \multirow[t]{2}{*}{ Scopoletin } & Oak medium toasted wood & $260.03 \mu \mathrm{g} / \mathrm{g}$ & Alañón et al., 2011 \\
\hline & Chestnut medium toasted wood & $285.85 \mu \mathrm{g} / \mathrm{g}$ & Alañón et al., 2011 \\
\hline Sinapaldehyde & Oak barrel aged brandy & $7700 \mathrm{mg} / \mathrm{L}$ & Rodríguez-Solana et al., 2014 \\
\hline \multirow[t]{3}{*}{ Syringaldehyde } & Seasoned cherry wood & $1-10 \mu \mathrm{g} / \mathrm{g}$ & De Rosso et al., 2009 \\
\hline & Seasoned chestnut wood & $>10 \mu \mathrm{g} / \mathrm{g}$ & De Rosso et al., 2009 \\
\hline & Seasoned oak wood & $>10 \mu \mathrm{g} / \mathrm{g}$ & De Rosso et al., 2009 \\
\hline
\end{tabular}




\begin{tabular}{llll}
\hline Phenolic compound & Source & Concentration & References \\
\hline & Toasted chestnut wood & $374.00 \mu \mathrm{g} / \mathrm{g}$ & Sanz et al., 2010b \\
& Oak aged brandy & $12200 \mathrm{mg} / \mathrm{L}$ & Rodríguez-Solana et al., 2014 \\
& Sessile oak aged brandy & $8200 \mathrm{mg} / \mathrm{L}$ & Rodríguez-Solana et al., 2014 \\
Syringic acid & Seasoned chestnut wood & $7.38 \mu \mathrm{g} / \mathrm{g}$ & Sanz et al., 2010b \\
& Toasted chestnut wood & $152.00 \mu \mathrm{g} / \mathrm{g}$ & Sanz et al., 2010b \\
Vanillic acid & Oak wood & $108.81 \mu \mathrm{g} / \mathrm{g}$ & Alañón et al., 2011 \\
& Sessile wood & $98.49 \mu \mathrm{g} / \mathrm{g}$ & Alañón et al., 2011 \\
\hline Vanillin & Heat treated oak wood & $71.23 \mu \mathrm{g} / \mathrm{g}$ & Alañón et al., 2011 \\
& Heat treated chestnut wood & $63.61 \mu \mathrm{g} / \mathrm{g}$ & Alañón et al., 2011 \\
& $163.00 \mu \mathrm{g} / \mathrm{g}$ & Sanz et al., 2010b \\
& Heat treated cherry wood & $30.38 \mu \mathrm{g} / \mathrm{g}$ & Alañón et al., 2011 \\
& Seasoned chestnut wood & $20.5 \mu \mathrm{g} / \mathrm{g}$ & Sanz et al., 2010b \\
& Oak wood aged grape marc distillate & $4.92 \mathrm{mg} / \mathrm{L}$ & Rodríguez-Solana et al., 2017 \\
& Oak aged brandy & $2800 \mathrm{mg} / \mathrm{L}$ & Rodríguez-Solana et al., 2014 \\
& Sessile oak aged brandy & $2400 \mathrm{mg} / \mathrm{L}$ & Rodríguez-Solana et al., 2014 \\
\hline
\end{tabular}

